\title{
Impact of Split and Re-Entrant Type Piston Bowl Geometry Fuelled with Pre Heated Diesel and Biodiesel on a Compression Ignition Engine Characteristics
}

Mohan Das Akkur Neele Gowda ( $\square$ mohandasakkur@gmail.com )

Dayananda Sagar College of Engineering https://orcid.org/0000-0003-4670-9077

Hanumanahalli Kambadarangappa Shivanand

University Visvesvaraya College of Engineering

Harish Gangaiah

University Visvesvaraya College of Engineering

Bhaskar Hindisigere Bytarangaiah

Sri Siddhartha Institute of Technology

Jagannatha Tumkur Doddaiah

HMS Institute of Technology

Shreyas Nagaraj

Dayananda Sagar College of Engineering

\section{Research Article}

Keywords: Preheated biodiesel, Hemispherical Piston Bowl Geometry (HPBG), Toroidal or Split type Piston Bowl Geometry (SPBG), Re-Entrant Piston Bowl Geometry (RPBG), ASTM standards

Posted Date: February 15th, 2021

DOl: https://doi.org/10.21203/rs.3.rs-178574/v1

License: (c) (1) This work is licensed under a Creative Commons Attribution 4.0 International License. Read Full License 


\section{Abstract}

The present investigation is carried out on biodiesel practicability over the existing non-renewable fuel due to its environmental dilapidation effect and oil crisis. Biodiesel was extracted from crude oil by transesterification, and its properties have been compared with those of neat diesel according to ASTM standards. Then, the blends of biodiesel are prepared for experimental analysis. Experimental results from our previous research study, the best blend was optimized. Then, the standard $\mathrm{Cl}$ engine with Hemispherical Piston Bowl Geometry (HPBG) is modified to Toroidal or Split type Piston Bowl Geometry (TPBG) and Re-Entrant Piston Bowl Geometry (RPBG). Experimental works were carried out for preheated optimized blend, neat diesel with modified Piston Bowl Geometries. The engine characteristics results were compared with these altered conditions. The modified PBG with preheated biodiesel blend resulted in better Performance and Combustion characteristics. The preheated biodiesel blends indicated significant depletion in the emission of harmful particulate matter such as $\mathrm{CO}, \mathrm{NO}_{x^{\prime}}$, and unburnt Hydrocarbons.

\section{Introduction}

Recent investigations and surveys in the field of fuels have shown that the usage and exploitation of nonrenewable fossil fuels have increased rapidly. With the ever-growing industries and use of motor vehicles, the world will soon need an alternate energy source form. The existing fuels such as diesel and petrol are depleting at an alarming rate, and the use of these fuels adds up enormously to the atmosphere's pollution levels. Researchers have been looking for an alternate source whose performance is comparable to diesel, keeping in mind the extinction and pollution aspects. One such alternate source which was found promising by the researchers is biodiesel [1-3].

Biodiesel is extracted from plants and animals and is found to be compatible with existing diesel engines. Biodiesel contains long-chain fatty esters and is obtained by reacting waste vegetable oils, animal fats with alcohol [4]. Generally, diesel is mixed with a proportionate amount of biodiesel known as Blends. Investigations have revealed that $20 \%$ blend is compatible with existing engines with very few modifications to be carried out. The history of biodiesel dates back to 1853, when Patrick Duffey conducted transesterification of vegetable oil. In the year 1937, G. Chavanne of University of Brussels was granted a patent for transforming vegetable oils for their uses as fuels. This is the first significant production of what is called biodiesel today [5]. Investigations revealed that biodiesel, when used as a fuel, significantly reduced the $\mathrm{CO}, \mathrm{HC}, \mathrm{PM}$ emissions into the atmosphere. In contrast, in a few cases, the $\mathrm{NO}_{x}$ emissions seemed to have increased along with increased fuel consumption. Biodiesel has a higher cetane number, a higher flash point, better lubrication properties, better biodegradable properties than diesel. Some of biodiesel's concerns are higher fuel consumption, engine wear, and a viscosity [6-8]. Further, it has been seen higher viscosity and biodiesel density even though after esterification, this intended to focus on preheating of fuel before sending into the engine cylinder to improve the characterization and engine performance $[9,10]$. 
Specific fuel consumption and engine characteristics depend on the air-fuel mixture's movement in the combustion chamber. The burning of charge in the chamber is greatly influenced by the piston bowl's profile leading the effective flow movement to the air-fuel mixture. Swirl movement of air is the movement around the circumference of the piston bowl geometry; as it moves, the increase in velocity leads to better air-fuel mixing to result in incomplete combustion and reduced emissions. The standard hemispherical PBG is modified into the split (toroidal) and re-entrant type [11-14].

Jaichandar et al [15]. Investigated the effect of two modified PBGs namely toroidal PBG and shallow depth PBG on a diesel engine fuelled with Pongamia Oil Methyl Ester (POME). The results showcased that the higher brake thermal efficiency and lower specific fuel consumption with the B20 blend compared to diesel. The emission characteristics indicated a significant reduction in carbon monoxide, particulate matter, and unburnt hydrocarbons, but the $\mathrm{NO}_{\mathrm{x}}$ emission level increased.

Lingesan et al [16]. Studied the diesel engine characteristics when chlorela emersonni was used as the fuel. Blends of $10,20,30$, and $100 \%$ were prepared. The findings indicated that B20 showed the most efficient results. The emissions showed a reduction in carbon monoxide, unburnt hydrocarbons, and smoke levels, whereas NOx levels increased.

Vedharaj et al [17]. Investigated the modified combustion bowl geometry of $\mathrm{Cl}$ engine fuelled with kapok biodiesel. Different mix from $20 \%$ to $100 \%$ of biodiesel were prepared. The standard PBG was modified into trapezoidal type PBG and toroidal type PBG. The results indicated that toroidal type PBG showed higher performance and fewer emission characteristics than trapezoidal and hemispherical PBGs.

Venkata et al [18]. Examined the consequences of shallow depth, toroidal and hemispherical PBGs on the performance and emission characteristics. The results revealed that toroidal PBG showed better characteristics when compared to the other two. The brake thermal efficiency increased by $10 \%$ with toroidal PBG when the B20 blend was used. The emissions of carbon monoxide, unburnt hydrocarbons, and opacity were lessened by $13 \%, 11 \%$, and $10 \%$, respectively.

Sankar Ganesh et al [19]. Investigated the effect of standard PBG modification into a deep bowl and toroidal PBGs fuelled with grape seed oil methyl ester. It was observed that deep bowl PBG showed better performance and emission characteristics when compared to the other. It was also noted that the $\mathrm{NO}_{\mathrm{x}}$ emission levels also decreased.

Dilip Kumar Bora1 et al [20]. Extracted biodiesel by mixing equal proportions of polongha oil, jatropha oil, and Karanja oil and investigated its effect on $\mathrm{Cl}$ engine's performance and emission characteristics. It was observed that up to the B40 blend, the brake thermal efficiency increases but above that proportion, the thermal efficiency decreases.

Prakash $\mathrm{T}$ et al [21]. Examined the impact of mixing castor oil and pine biodiesel on the combustion characteristics of a diesel engine. The result analysis's optimum indicated was $30 \%$ of pine oil and $70 \%$ 
of castor oil. This blend resulted in increased thermal efficiency and reduced emissions. The NOx levels were also observed to have decreased.

Channappagoudra et al., [22] examine the engine traits of toroidal piston bowl geometry (TPBG). In this study, they modified HPBG to TPBG for dairy scum biodiesel $\mathrm{Cl}$ engine. The results showcased that the $B T E$, the rate of heat energy released, the pressure rise rate, and in-cylinder pressure were increased and less BSFC for both diesel and B20 fuel than typical PBG values. Further, $\mathrm{HC}$ emissions were decreased, and shorter ignition delay and less combustion duration were observed for the TPBG operated $\mathrm{Cl}$ engine.

Kumar., [23] reported the influence of Toroidal shape with a peripheral cut on the piston top's circumference, Hemisphere shape with Spherical Arc on Circumference of the piston top on $\mathrm{Cl}$ engine characteristics. The results inferred that the modified geometries gave an improved performance, combustion, and fewer emissions except for NOx than that of standard PBG.

Ganji et al., [24] studied the different PBG's CFD models for a Cl engine. They created the hemispherical, shallow depth and toroidal shape piston bowl. Then they examined the effects of different PBG's on the $\mathrm{Cl}$ engine. The results inferred that TCC geometry gave a better swirl motion than the other geometries. Further, TCC geometry gave an improved performance and fewer emissions with that of the baseline design.

Lalvani et al., [25] investigated the effect of novel design of PBG with adelfa biodiesel at $20 \%$ blend on $\mathrm{Cl}$ engine. The results inferred that improved performance and combustion traits and fewer exhaust emissions except for NOx for A20 blend the novel designed PBG compared to HPBG.

Ramesh Bapu et al., [26] examine the suitability of modified hemispherical piston bowl geometry [MHCC] for variable compression ratio $\mathrm{Cl}$ engine. They have carried out a simulation study on $\mathrm{MHCC}$ by using Ansys Fluent software. The results concluded that the MHCC has better swirl motion than HCC and the $\mathrm{MHCC}$ was a better choice for the conventional engine at all operating conditions.

Varun Singh et al., [27] reviewed and discussed the consequence of various piston bowl design on $\mathrm{Cl}$ engine. They showcased a deficiency in performance when biodiesel was used in the $\mathrm{Cl}$ engine, which could be overcome by modifying the combustion chamber geometry. Finally, from elaborate discussions, they concluded that small modifications in the piston crown enhanced the performance and combustion attributes and fewer emissions than conventional piston bowl design.

From the above widespread literature, it was seen that only a few works had been done on the different piston bowl geometries (PBG) with various biodiesel to evaluate the engine characteristics. And also, there are no many investigations on preheating of fuel and modified PBG to improve the performance and reduce the $\mathrm{Cl}$ engine emissions. Thus, the current study aims to evaluate the impact of SPBG and RPBG on a Cl engine fuelled with and without preheated fuels, and the best PBG has to be optimized based on the engine characteristics studies. Therefore, in this study, comprehensive investigations have been done on the modified PBG's namely SPBG/TPBG and RPBG, along with preheated fuel, to evaluate 
the best PBG shape for with and without preheated fuelled $\mathrm{Cl}$ engine by likening the results of modified PBG's with Standard PBG.

\section{Materials And Methods}

\subsection{Extraction of Biodiesel}

Calophyllum Inophyllum non-edible oil was selected in the present study because of its wide availability, low cost, and high oil content. Initially, FFA was tested, and it was found to be more than $2 \%$, which is not acceptable as per ASTM standards. Therefore, the Transesterification method was adopted to reduce the FFA by less than $2 \%$ and maintain the other properties as per ASTM standards. The detailed biodiesel extraction processes have been discussed in our previous research work [28]. The produced biodiesel is blended in different ratios. $\mathrm{Cl} 20$ blend is made up of $20 \%$ Biodiesel and $80 \%$ Pure Diesel, $\mathrm{Cl} 100$ blend consists of $100 \%$ Biodiesel and is entirely free from diesel, making it the purest biodiesel, and ' $D$ ' is neat diesel with $0 \%$ Biodiesel. These blends have been prepared to carry out the engine test. The photographic view of the Transesterification test arrangement and biodiesel blends are portrayed in Figure 1, and

2.Table 1 portrays the biodiesel blends with neat diesel physical and chemical characteristics.

Table 1 Biodiesel blends with neat diesel physical and chemical characteristics

\begin{tabular}{|c|c|c|c|c|c|c|c|c|}
\hline Description & $\begin{array}{l}\text { Flash } \\
\text { point } \\
\left({ }^{\circ} \mathrm{C}\right)\end{array}$ & $\begin{array}{l}\text { Fire } \\
\text { point } \\
\left({ }^{\circ} \mathrm{C}\right)\end{array}$ & $\begin{array}{l}\text { Kinetic } \\
\text { viscosity } \\
@ 40 \circ C \\
\left(\mathrm{~m}^{2} / \mathrm{s}\right) \\
\times 10^{-4}\end{array}$ & $\begin{array}{l}\text { Gross } \\
\text { calorific } \\
\text { value } \\
(\mathrm{kJ} / \mathrm{kg})\end{array}$ & $\begin{array}{l}\text { Net } \\
\text { calorific } \\
\text { value } \\
(\mathrm{kJ} / \mathrm{kg})\end{array}$ & $\begin{array}{l}\text { Specific } \\
\text { gravity } \\
\text { @15oC }\end{array}$ & $\begin{array}{l}\text { Free } \\
\text { fatty } \\
\text { acid } \\
(\%)\end{array}$ & $\begin{array}{l}\text { Cetane } \\
\text { Number }\end{array}$ \\
\hline $\begin{array}{l}\text { Cl Crude } \\
\text { Oil }\end{array}$ & 218 & 238 & 1.27 & 37050.99 & 34323.86 & 0.95 & 25.3 & - \\
\hline Neat Diesel & 52 & 58 & 0.06 & 44000 & 42500 & 0.83 & - & 47 \\
\hline $\mathrm{Cl} 20$ & 73.6 & 78.8 & 0.0648 & 42901.07 & 41173.88 & 0.845 & - & - \\
\hline Cl100 & 160 & 162 & 0.084 & 38505.352 & 35869.43 & 0.906 & 1.95 & 56 \\
\hline
\end{tabular}

\subsection{Modifications in Piston bowl geometry}

In this study, three various piston bowl geometries (PBG's) have been used, shown in Figures 3, 4, and 5. These geometries were used to optimize the best performance traits in the $\mathrm{Cl}$ engine. Figure 3 depicts the standard PBG (hemispherical combustion chamber). Figure 4 and figure 5 are the modified piston bowl geometry used for the experiment work. Figure 4 is the toroidal type piston bowl geometry, and Figure 5 shows the re-entrant type PBG. The specification table of all the PBGs are depicted in Table 2. 
Table 2 Piston geometry specifications

\begin{tabular}{|llll|}
\hline Particulars & \multicolumn{2}{l|}{ Type of Piston } & \\
\cline { 2 - 4 } & Standard (HPBG) & TPBG & REPBG \\
\hline Bowl Volume $\left(\mathrm{mm}^{3}\right)$ & $36,811.08$ & $36,811.08$ & 28952.98 \\
\hline Throat diameter(mm) & 52 & 52 & 48 \\
\hline Bowl depth $(\mathrm{mm})$ & 26 & 22 & 20.0 \\
\hline Piston diameter $(\mathrm{mm})$ & 87.42 & 87.42 & 87.42 \\
\hline
\end{tabular}

\subsection{Experimental Set-up and Experimental Tests}

In this investigation, $\mathrm{Cl}$ engine with four strokes, one cylinder setup was used. The engine has a maximum power of $5.2 \mathrm{~kW}$ and $1500 \mathrm{rpm}$ constant speed with varying loads from $0-100 \%$ by the eddy current dynamometer. 'Engine soft' software was used for online data recording, and the engine was fully computerized. The exhaust pipe emissions like $\mathrm{CO}, \mathrm{HC}$, and NOx were measured by using five gas analyzer. A cold trap and sieve elements were attached to the gas analyzer to preclude it from dust particles and moisture from the dissipate emissions. An accelerator smoke meter was used to measure the smoke density. The photographic view of the engine test rig is shown in Figure 6. The engine test rig, dynamometer, gas analyzer, and smoke meter specification are illustrated in tables $3,4,5$, and 6 . The engine was run with the standard HPBG, and the baseline reading was recorded with diesel and biodiesel samples. In this experimental work, two modified PBGs were used. The two geometries used were toroidal/split type and re-entrant type PBG. The standard hemispherical piston bowl geometry was used without any modification to record the baseline readings. The engine achieved steady-state condition by allowing it to run with diesel for about 30 minutes. Further, the engine's steady-state condition was monitor by observing the exhaust water temperature, and it is limited to $50-55^{\circ} \mathrm{C}$. The engine loads various from 0 to $100 \%$ at an interval of $25 \%$. To use alternate fuel after completing the engine test with convention fuel, all the fuel used in the previous experiment was completely drained out from the tank and fuel pipe. Then $\mathrm{Cl}$ fuel was filled into the tank, and the same procedure was followed for each sample. After completing the test for standard PBG, the same procedure was followed for TBPG and RPBG, and the results were recorded. The accuracy of the experimental setup was found out by doing an error analysis.

Table 3 Specifications of Engine setup 


\begin{tabular}{|ll|}
\hline Parameters & Dimensions \\
\hline Type & $\begin{array}{l}\text { Number of stroke: } 4 \\
\text { Number of cylinder: } 1 \\
\text { Cooling Type: Vertical water cooled diesel engine }\end{array}$ \\
\hline Maximum power & $5.2 \mathrm{kw}$ \\
\hline Maximum speed & $1500 \mathrm{rpm}$ \\
\hline Bore diameter (D) & $87.5 \mathrm{~mm}$ \\
\hline displacement length (L) & $110 \mathrm{~mm}$ \\
\hline Compression Ratio & $17.5: 1$ \\
\hline
\end{tabular}

Table 4 Eddy current dynamometer specification

\begin{tabular}{|ll|}
\hline Parameters & Dimensions \\
\hline Make & Techno Mech \\
\hline Model & TMEC-10 \\
\hline $\mathrm{kW}$ & $\mathrm{Nm}$ *RPM/9549305 \\
\hline Max kW & 7.5 \\
\hline Dynamometer arm length & $185 \mathrm{~mm}$ \\
\hline RPM & $1500-6000$ \\
\hline
\end{tabular}

Table 5 Gas Analyzer Specification

\begin{tabular}{|ll|}
\hline Parameters & Resolution \\
\hline Model & AVL DI GAS 444 N (Five Gas Analyzer) \\
\hline $\mathrm{CO}(0-15 \% \mathrm{Vol})$ & $0.0001 \% \mathrm{Vol}$ \\
\hline $\mathrm{HC}(0-20000 \mathrm{ppm}$ Vol $)$ & $1 \mathrm{ppm} / 10 \mathrm{ppm}$ \\
\hline $\mathrm{CO}_{2}(0-20 \% \mathrm{Vol})$ & $0.1 \% \mathrm{Vol}$ \\
\hline $\mathrm{O}_{2}(0-25 \% \mathrm{Vol})$ & $0.01 \% \mathrm{Vol}$ \\
\hline $\mathrm{NO}(0-6000 \mathrm{ppm} \mathrm{Vol})$ & $1 \mathrm{ppm} \mathrm{Vol}$ \\
\hline
\end{tabular}


Table 6 Smoke meter Specification

\begin{tabular}{|ll|}
\hline Parameters & Resolution \\
\hline Model & AVL 437C Smoke meter \\
\hline Opacity (0-100\%) & $0.1 \%$ \\
\hline Absorption (K Value) & $0-99-99 \mathrm{~m}^{-1} 0.01 \mathrm{~m}^{-1}$ \\
\hline
\end{tabular}

\subsubsection{Uncertainty Calculation}

Before conducting regular experiments, it is essential to know the instrumentation error to get accurate results. Therefore, the preliminary experiment has repeated a minimum of 10times at the standard operating conditions, and results were recorded. Then average values were taken. Further, the percentage uncertainty of various devices was calculated by the root mean square method. The total uncertainty of the instruments used was calculated as follows

Total uncertainty of the instruments used $=$ Square root of $\left\{(\text { Load uncertainty })^{2}+(\right.$ Exhaust Temperature Uncertainty $)^{2}+(\text { Fuel Consumption Uncertainty })^{2}+(\text { Speed Uncertainty })^{2}+(\text { CO Uncertainty })^{2}+(\mathrm{HC}$ Uncertainty $)^{2}+\left(\mathrm{CO}_{2} \text { Uncertainty }\right)^{2}+\left(\mathrm{O}_{2} \text { Uncertainty }\right)^{2}+\left(\mathrm{NO}_{\mathrm{X}} \text { Uncertainty }\right)^{2}+(\text { Smoke Uncertainty })^{2}+$ (Cylinder Pressure Uncertainty $\left.)^{2}+(\text { Crank angle Uncertainty })^{2}\right\}$.

$=$ Square root of $\left\{(0.2)^{2}+(0.1)^{2}+(1)^{2}+(0.2)^{2}+(0.1)^{2}+(0.1)^{2}+(0.15)^{2}+(0.1)^{2}+(0.2)^{2}+(0.1)^{2}+(1)^{2}+\right.$ $\left.(0.1)^{2}\right\}=1.48 \%$

The total improbability of the instrument used is $1.48 \%$. The comprehensive Uncertainty, Accuracy, and Range of various measuring instruments are shown in Table 7.

Table 7 Uncertainty, Accuracy and Range of various measuring instruments 


\begin{tabular}{|c|c|c|c|c|c|c|}
\hline $\begin{array}{l}\text { Sl. } \\
\text { No }\end{array}$ & $\begin{array}{l}\text { Measurement } \\
\text { Device }\end{array}$ & Measurement & Range & Accuracy & $\begin{array}{l}\text { Uncertainty } \\
\text { (\%) }\end{array}$ & $\begin{array}{l}\text { Measurement } \\
\text { Method }\end{array}$ \\
\hline 1 & $\begin{array}{l}\text { Load } \\
\text { Indicator }\end{array}$ & Load(W) & $250-6000$ & $\pm 10 \mathrm{~W}$ & 0.2 & $\begin{array}{l}\text { Strain gauge type } \\
\text { load cell }\end{array}$ \\
\hline 2 & $\begin{array}{l}\text { Temperature } \\
\text { Indicator }\end{array}$ & $\begin{array}{l}\text { Exhaust } \\
\text { Temperature } \\
\left({ }^{\circ} \mathrm{C}\right)\end{array}$ & $0-900$ & $\pm 1^{\circ} \mathrm{C}$ & 0.1 & Thermocouple \\
\hline 3 & Barrette & $\begin{array}{l}\text { Fuel } \\
\text { consumption } \\
\text { (cc) }\end{array}$ & $1-30$ & $\pm 0.2 \mathrm{cc}$ & 1 & $\begin{array}{l}\text { Volumetric } \\
\text { measurement }\end{array}$ \\
\hline 4 & Speed Sensor & Speed (rpm) & $1500-6000$ & \pm 10 rpm & 0.2 & $\begin{array}{l}\text { Magnetic pickup } \\
\text { type }\end{array}$ \\
\hline \multirow[t]{5}{*}{5} & \multirow{5}{*}{$\begin{array}{l}\text { Exhaust Gas } \\
\text { Analyser }\end{array}$} & $\mathrm{CO}$ & (0-15\% Vol) & $\pm 0.02 \%$ & 0.1 & \multirow{3}{*}{$\begin{array}{l}\text { Nondispersive } \\
\text { infrared sensor } \\
\text { (NDIR) }\end{array}$} \\
\hline & & $\mathrm{HC}$ & $\begin{array}{l}\text { (0-20000 } \\
\text { ppm Vol) }\end{array}$ & $\pm 20 p p m$ & 0.1 & \\
\hline & & $\mathrm{CO}_{2}$ & $(0-20 \%$ Vol) & $\pm 0.03 \%$ & 0.15 & \\
\hline & & $\mathrm{O}_{2}$ & $(0-25 \%$ Vol) & $\pm 0.02 \%$ & 0.1 & $\begin{array}{l}\text { Ultrasonic Oxygen } \\
\text { Sensor }\end{array}$ \\
\hline & & NOX & $\begin{array}{l}(0-6000 \\
\text { ppm Vol) }\end{array}$ & $\pm 10 p p m$ & 0.2 & $\begin{array}{l}\text { Electrochemical } \\
\text { measurement }\end{array}$ \\
\hline 6 & Smoke meter & Smoke & $(0-100 \%)$ & $0.1 \%$ & 0.1 & Smoke meter \\
\hline 7 & $\begin{array}{l}\text { Pressure } \\
\text { Transducer }\end{array}$ & Pressure (bar) & $0-110$ & \pm 1 bar & 1 & $\begin{array}{l}\text { Piezoelectric } \\
\text { sensor }\end{array}$ \\
\hline 8 & $\begin{array}{l}\text { Crank angle } \\
\text { encoder }\end{array}$ & Crank angle & $0-720$ & \pm 1 & 0.1 & $\begin{array}{l}\text { Magnetic pickup } \\
\text { type }\end{array}$ \\
\hline
\end{tabular}

\subsubsection{Rate of Energy share calculation}

In this study, the energy share rate of different proportions of fuel has been calculated to know its contribution of energy in each load varying conditions. The same has been tabulated in Tables 8, 9, 10, 11,12 , and 13.

Table 8 Energy share calculation for HPBG at surrounding Temperature 


\begin{tabular}{|llllllll|}
\hline $\begin{array}{l}\text { Load } \\
(\%)\end{array}$ & $\begin{array}{l}\text { Mass flow } \\
\text { rate of } \\
\text { diesel in } \\
\mathbf{k g} / \mathbf{h}\end{array}$ & $\begin{array}{l}\text { Mass flow } \\
\text { rate of } \\
\text { diesel in } \\
\mathbf{k g} / \mathbf{h}\end{array}$ & $\begin{array}{l}\text { Energy } \\
\text { Share by } \\
\text { Diesel(KW) }\end{array}$ & $\begin{array}{l}\text { Energy } \\
\text { Share by } \\
\text { B20(KW) }\end{array}$ & $\begin{array}{l}\text { Total } \\
\text { Energy } \\
\text { share } \\
(\mathrm{KW})\end{array}$ & $\begin{array}{l}\text { \% Energy } \\
\text { share by } \\
\text { Diesel } \\
(\mathrm{KW})\end{array}$ & $\begin{array}{l}\text { \% Energy } \\
\text { share by } \\
\mathbf{B 2 0}(\mathrm{KW})\end{array}$ \\
\hline 0 & 0.3 & 0.35 & 3.54 & 4.003 & 7.54 & 46.95 & 53.04 \\
\hline 25 & 0.55 & 0.61 & 6.49 & 6.97 & 13.46 & 48.21 & 51.78 \\
\hline 50 & 0.75 & 0.86 & 8.85 & 9.38 & 18.23 & 48.54 & 51.45 \\
\hline 75 & 1.05 & 1.12 & 12.39 & 12.8 & 25.21 & 49.18 & 50.81 \\
\hline 100 & 1.29 & 1.37 & 15.22 & 15.87 & 31.1 & 48.96 & 51.03 \\
\hline
\end{tabular}

Table 9 Energy share calculation for HPBG at $50^{\circ} \mathrm{C}$ Temperature

\begin{tabular}{|llllllll|}
\hline $\begin{array}{l}\text { Load } \\
(\%)\end{array}$ & $\begin{array}{l}\text { Mass flow } \\
\text { rate of } \\
\text { diesel in } \\
\mathbf{k g} / \mathbf{h}\end{array}$ & $\begin{array}{l}\text { Mass flow } \\
\text { rate of } \\
\text { diesel in } \\
\mathbf{k g} / \mathbf{h}\end{array}$ & $\begin{array}{l}\text { Energy } \\
\text { Share by } \\
\text { Diesel(KW) }\end{array}$ & $\begin{array}{l}\text { Energy } \\
\text { Share by } \\
\text { B20(KW) }\end{array}$ & $\begin{array}{l}\text { Total } \\
\text { Energy } \\
\text { share } \\
(\mathbf{K W})\end{array}$ & $\begin{array}{l}\text { \% Energy } \\
\text { share by } \\
\text { Diesel } \\
(\mathrm{KW})\end{array}$ & $\begin{array}{l}\text { \% Energy } \\
\text { share by } \\
\mathbf{B 2 0}(\mathrm{KW})\end{array}$ \\
\hline 0 & 0.35 & 0.35 & 4.13 & 4.003 & 8.13 & 50.79 & 49.21 \\
\hline 25 & 0.6 & 0.61 & 7.09 & 6.97 & 14.07 & 50.43 & 49.56 \\
\hline 50 & 0.8 & 0.86 & 9.77 & 9.38 & 19.15 & 51.02 & 48.97 \\
\hline 75 & 1.05 & 1.12 & 12.39 & 12.8 & 25.21 & 49.18 & 50.82 \\
\hline 100 & 1.29 & 1.37 & 15.22 & 15.87 & 31.1 & 48.96 & 51.04 \\
\hline
\end{tabular}

Table 10 Energy share calculation for TPBG at surrounding Temperature

\begin{tabular}{|llllllll|}
\hline $\begin{array}{l}\text { Load } \\
(\%)\end{array}$ & $\begin{array}{l}\text { Mass flow } \\
\text { rate of } \\
\text { diesel in } \\
\mathbf{k g} / \mathbf{h}\end{array}$ & $\begin{array}{l}\text { Mass flow } \\
\text { rate of } \\
\text { diesel in } \\
\mathbf{k g} / \mathbf{h}\end{array}$ & $\begin{array}{l}\text { Energy } \\
\text { Share by } \\
\text { Diesel(KW) }\end{array}$ & $\begin{array}{l}\text { Energy } \\
\text { Share by } \\
\text { B20(KW) }\end{array}$ & $\begin{array}{l}\text { Total } \\
\text { Energy } \\
\text { share } \\
(\mathrm{KW})\end{array}$ & $\begin{array}{l}\text { \% Energy } \\
\text { share by } \\
\text { Diesel } \\
\text { (KW) }\end{array}$ & $\begin{array}{l}\text { \% Energy } \\
\text { share by } \\
\text { B20 (KW) }\end{array}$ \\
\hline 0 & 0.35 & 0.35 & 4.13 & 4.003 & 8.13 & 50.79 & 49.21 \\
\hline 25 & 0.6 & 0.61 & 7.09 & 6.97 & 14.07 & 50.43 & 49.56 \\
\hline 50 & 0.8 & 0.86 & 9.77 & 9.38 & 19.15 & 51.02 & 48.97 \\
\hline 75 & 1.05 & 1.12 & 12.39 & 12.8 & 25.21 & 49.18 & 50.82 \\
\hline 100 & 1.29 & 1.37 & 15.22 & 15.87 & 31.1 & 48.96 & 51.04 \\
\hline
\end{tabular}

Table 11 Energy share calculation for TPBG at $50^{\circ} \mathrm{C}$ Temperature 


\begin{tabular}{|llllllll|}
\hline $\begin{array}{l}\text { Load } \\
(\%)\end{array}$ & $\begin{array}{l}\text { Mass flow } \\
\text { rate of } \\
\text { diesel in } \\
\mathbf{k g} / \mathbf{h}\end{array}$ & $\begin{array}{l}\text { Mass flow } \\
\text { rate of } \\
\text { diesel in } \\
\mathbf{k g} / \mathbf{h}\end{array}$ & $\begin{array}{l}\text { Energy } \\
\text { Share by } \\
\text { Diesel(KW) }\end{array}$ & $\begin{array}{l}\text { Energy } \\
\text { Share by } \\
\text { B20(KW) }\end{array}$ & $\begin{array}{l}\text { Total } \\
\text { Energy } \\
\text { share } \\
(\mathrm{KW})\end{array}$ & $\begin{array}{l}\text { \% Energy } \\
\text { share by } \\
\text { Diesel } \\
(\mathrm{KW})\end{array}$ & $\begin{array}{l}\text { \% Energy } \\
\text { share by } \\
\text { B20 (KW) }\end{array}$ \\
\hline 0 & 0.35 & 0.35 & 4.13 & 4.003 & 8.13 & 50.79 & 49.21 \\
\hline 25 & 0.6 & 0.61 & 7.09 & 6.97 & 14.07 & 50.43 & 49.56 \\
\hline 50 & 0.8 & 0.86 & 9.77 & 9.38 & 19.15 & 51.02 & 48.97 \\
\hline 75 & 1.05 & 1.12 & 12.39 & 12.8 & 25.21 & 49.18 & 50.82 \\
\hline 100 & 1.29 & 1.37 & 15.22 & 15.87 & 31.1 & 48.96 & 51.04 \\
\hline
\end{tabular}

Table 12 Energy share calculation for RPBG at surrounding Temperature

\begin{tabular}{|llllllll|}
\hline $\begin{array}{l}\text { Load } \\
(\%)\end{array}$ & $\begin{array}{l}\text { Mass flow } \\
\text { rate of } \\
\text { diesel in } \\
\mathbf{k g} / \mathbf{h}\end{array}$ & $\begin{array}{l}\text { Mass flow } \\
\text { rate of } \\
\text { diesel in } \\
\mathbf{k g} / \mathbf{h}\end{array}$ & $\begin{array}{l}\text { Energy } \\
\text { Share by } \\
\text { Diesel(KW) }\end{array}$ & $\begin{array}{l}\text { Energy } \\
\text { Share by } \\
\text { B20(KW) }\end{array}$ & $\begin{array}{l}\text { Total } \\
\text { Energy } \\
\text { share } \\
(\mathrm{KW})\end{array}$ & $\begin{array}{l}\text { \% Energy } \\
\text { share by } \\
\text { Diesel } \\
(\mathrm{KW})\end{array}$ & $\begin{array}{l}\text { \% Energy } \\
\text { share by } \\
\mathbf{B 2 0}(\mathrm{KW})\end{array}$ \\
\hline 0 & 0.35 & 0.35 & 4.13 & 4.003 & 8.13 & 50.79 & 49.21 \\
\hline 25 & 0.6 & 0.66 & 7.09 & 7.55 & 14.65 & 48.45 & 51.55 \\
\hline 50 & 0.8 & 0.91 & 9.77 & 10.41 & 20.18 & 48.43 & 51.57 \\
\hline 75 & 1.05 & 1.12 & 12.39 & 12.85 & 25.24 & 49.11 & 50.89 \\
\hline 100 & 1.29 & 1.42 & 15.23 & 16.24 & 31.47 & 48.39 & 51.61 \\
\hline
\end{tabular}

Table 13 Energy share calculation for RPBG at $50^{\circ} \mathrm{C}$ Temperature

\begin{tabular}{|llllllll|}
\hline $\begin{array}{l}\text { Load } \\
(\%)\end{array}$ & $\begin{array}{l}\text { Mass flow } \\
\text { rate of } \\
\text { diesel in } \\
\mathbf{k g} / \mathbf{h}\end{array}$ & $\begin{array}{l}\text { Mass flow } \\
\text { rate of } \\
\text { diesel in } \\
\mathbf{k g} / \mathbf{h}\end{array}$ & $\begin{array}{l}\text { Energy } \\
\text { Share by } \\
\text { Diesel(KW) }\end{array}$ & $\begin{array}{l}\text { Energy } \\
\text { Share by } \\
\text { B20(KW) }\end{array}$ & $\begin{array}{l}\text { Total } \\
\text { Energy } \\
\text { share } \\
\text { (KW) }\end{array}$ & $\begin{array}{l}\text { \% Energy } \\
\text { share by } \\
\text { Diesel } \\
\text { (KW) }\end{array}$ & $\begin{array}{l}\text { \% Energy } \\
\text { share by } \\
\text { B20 (KW) }\end{array}$ \\
\hline 0 & 0.35 & 0.35 & 4.13 & 4.003 & 8.13 & 50.79 & 49.21 \\
\hline 25 & 0.6 & 0.61 & 7.09 & 6.97 & 14.07 & 50.43 & 49.57 \\
\hline 50 & 0.85 & 0.86 & 9.47 & 9.38 & 18.86 & 50.24 & 49.76 \\
\hline 75 & 1.05 & 1.12 & 12.39 & 12.81 & 25.2 & 49.18 & 50.82 \\
\hline 100 & 1.29 & 1.37 & 15.23 & 15.87 & 31.1 & 48.96 & 51.04 \\
\hline
\end{tabular}

\section{Result And Discussions}




\subsection{Influence of Split and Re-Entrant Type Piston Bowl Geometry with diesel and Cl20 biodiesel (with and without preheated) on Performance attributes}

The influence of different PBG's on BTHE for with and without preheated fuels at varying load conditions are depicted in Figures 7 (a) and (b). Refers to Figure 7(a) the BTHE results of without preheated fuels for D-HPBG, Cl 20-HPBG, Cl100-HPBG, D-TPBG, Cl20-TPBG, Cl100-TPBG, D-RPBG, Cl20-RPBG, Cl100-RPBG noted as $33.04,32.9,28.01,32.29,31.63,29.5,31.1,30.34$ and $28.36 \%$ respectively. The results indicated an improved BTHE in TPBG than those of RPBG values, and for the $\mathrm{Cl} 20$ blend, the BTHE is almost $4.08 \%$ higher than the RPBG at $100 \%$ engine load. This observation was made due to the better mixing of charge with previous unburnt gases existing in the chamber. This leads to the complete burning and high cylinder temperature and might cause long combustion duration, resulting in faster oxidation and evaporation. Further for preheated fuels at $500 \mathrm{C}$ [Refer Figure $7(\mathrm{~b})]$, the BTHE of D $50^{\circ} \mathrm{C}-\mathrm{HPBG}, \mathrm{Cl} 2050^{\circ} \mathrm{C}$

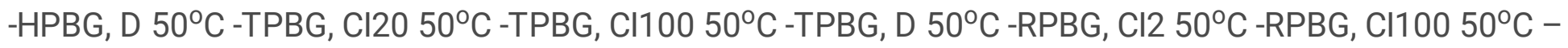
RPBG are $32.42,31.73,32.4,31.46,30.42,31.14,31.68$ and $28.35 \%$ respectively. From these results, it is cleared that preheated fuels gave higher BTHE than those without preheated fuels for different PBG's. This happened might be due to the lower viscosity of preheated fuels leading to the efficient vaporization of fuel, which gave higher BTHE than cold fuel [29-32].

Figure 8 (a) \& (b) illustrates the Impact of different PBG's on ITHE for with and without preheated fuels at varying load conditions. Figure 8(a) gives the variation of ITHE results for D-HPBG, Cl 20-HPBG, Cl100HPBG, D-TPBG, CI20-TPBG, Cl100-TPBG, D-RPBG, Cl20-RPBG, Cl100-RPBG, and they are noted as 45.78, $43.59,39.38,44.9,43.61,40.41,44.04,43.47$ and $39.68 \%$ respectively. Here, it is observed that for TPBG, the $\mathrm{Cl} 20$ fuel has approximately $0.32 \%$ higher ITHE than the RPBG. Further, for Preheated at $50^{\circ} \mathrm{C}$ fuel [Refer Figure (b)], the experimental ITHE of D50 ${ }^{\circ} \mathrm{C}-\mathrm{HPBG}, \mathrm{Cl} 2050^{\circ} \mathrm{C}-\mathrm{HPBG}, \mathrm{D} 50^{\circ} \mathrm{C}-\mathrm{TPBG}, \mathrm{Cl} 2050^{\circ} \mathrm{C}-$ TPBG, $\mathrm{Cl} 10050^{\circ} \mathrm{C}-\mathrm{TPBG}, \mathrm{D} 50^{\circ} \mathrm{C}$-RPBG, $\mathrm{Cl} 250^{\circ} \mathrm{C}$-RPBG, $\mathrm{Cl} 10050^{\circ} \mathrm{C}-\mathrm{RPBG}$ are 44.84, 44.37, 42.9, 43.2, $41.92,43.33,44.61$ and $41.92 \%$ respectively. It indicates the ITHE of preheated $\mathrm{Cl} 20$ fuel has increased by $2.4 \%$ for RPBG than the other PBGs and fuels. Further, it concludes that preheated fuels have an increase in ITHE than without preheated fuels. It might be happened due to effective vaporization of fuel results the complete combustion causes for the higher ITHE [29-32].

Figure 9 (a) \& (b) represents the effect of different PBG's on ME for with and without preheated fuels at varying load. Figure 9(a) refers to the disparity of ME results for D-HPBG, Cl 20-HPBG, Cl100-HPBG, DTPBG, Cl20-TPBG, Cl100-TPBG, D-RPBG, Cl20-RPBG, Cl100-RPBG, and they are noted as 72.18, 73.65, $70.11,71.91,72.54,73,70.62,69.79$ and $71.47 \%$ respectively. Here, it is observed that for TPBG, the Cl20 fuel has approximately $3.79 \%$ higher ME than the RPBG. Further, for Preheated at $50^{\circ} \mathrm{C}$ fuel [Refer Figure 
(b)], the experimental ME of D $50^{\circ} \mathrm{C}-\mathrm{HPBG}, \mathrm{Cl} 2050^{\circ} \mathrm{C}-\mathrm{HPBG}, \mathrm{D} 50^{\circ} \mathrm{C}-\mathrm{TPBG}, \mathrm{Cl} 2050^{\circ} \mathrm{C}-\mathrm{TPBG}, \mathrm{Cl} 10050^{\circ} \mathrm{C}$ -TPBG, D 50 ${ }^{\circ} \mathrm{C}$-RPBG, $\mathrm{Cl} 250^{\circ} \mathrm{C}$-RPBG, $\mathrm{Cl} 10050^{\circ} \mathrm{C}-\mathrm{RPBG}$ are $72.3,71.51,71.92,72.83,72.56,71.88$, 71.7 and $71.9 \%$ respectively. It indicates the ME of preheated $\mathrm{Cl} 20$ fuel increased by $1.13 \%$ for TPBG than the other PBGs and fuels. Furthermore, it has been inferred from Figure 9 (a) \& (b) that the preheated fuels have more ME than those of non preheated fuels. It might be happened due to effective vaporization of fuel results the complete combustion causes for the higher ME [29-32].

The influence of different PBG's on IP for with and without preheated fuels at varying load conditions are depicted in Figures 10 (a) and (b). Refers to Figure 10(a), the IP results of without preheated fuels for DHPBG, Cl 20-HPBG, Cl100-HPBG, D-TPBG, Cl20-TPBG, Cl100-TPBG, D-RPBG, Cl20-RPBG, Cl100-RPBG noted as $7,6.83,6.78,6.86,6.83,6.78,6.99,7.06$ and $6.87 \mathrm{~kW}$ respectively. The results indicated that there is an improved IP in RPBG than those of TPBG values, and for the $\mathrm{Cl} 20$ blend, the IP is almost $3.36 \%$ higher than the TPBG at $100 \%$ engine load. It happened might be due to high combustion pressure and temperature. Further, for preheated fuels at $50^{\circ} \mathrm{C}$ [Refer Figure $\left.7(\mathrm{~b})\right]$, the IP of $D 50^{\circ} \mathrm{C}-\mathrm{HPBG}, \mathrm{Cl} 2050^{\circ} \mathrm{C}$ HPBG, D 50 $0^{\circ} \mathrm{C}-\mathrm{TPBG}, \mathrm{Cl} 2050^{\circ} \mathrm{C}$-TPBG, Cl100 50 $0^{\circ} \mathrm{C}$-TPBG, D $50^{\circ} \mathrm{C} 8$-RPBG, Cl2 $50^{\circ} \mathrm{C}-\mathrm{RPBG}, \mathrm{Cl} 10050^{\circ} \mathrm{C}$ -RPBG are $6.85,6.95,6.89,6.76,6.8,6.88,6.98$ and $6.83 \mathrm{~kW}$ respectively. From these results, it is clear that preheated fuels have higher IP than cold fuels for different PBG's. The main reason for this variation is the efficient vaporization of fuel, which gave high combustion pressure [29-32].

Figure 11 (a) \& (b) indicates the influence of different PBG's on VE for with and without preheated fuels at varying load. Figure 11(a) refers to the disparity of VE results for D-HPBG, Cl 20-HPBG, CI100-HPBG, DTPBG, Cl20-TPBG, Cl100-TPBG, D-RPBG, Cl20-RPBG, Cl100-RPBG, and they are noted as 84.33, 82.17, $81.32,84.08,84.17,83.97,83.58,84.51$ and $83.72 \%$ respectively. From the obtained results, it is seen that VE increased for modified PBGs. Furthermore, for Preheated at $50^{\circ} \mathrm{C}$ fuel [Refer Figure $11(\mathrm{~b})$ ], the experimental VE of D $50^{\circ} \mathrm{C}-\mathrm{HPBG}, \mathrm{Cl} 2050^{\circ} \mathrm{C}-\mathrm{HPBG}, \mathrm{D} 50^{\circ} \mathrm{C}-\mathrm{TPBG}, \mathrm{Cl} 2050^{\circ} \mathrm{C}-\mathrm{TPBG}, \mathrm{Cl} 10050^{\circ} \mathrm{C}-\mathrm{TPBG}$, D 50 ${ }^{\circ} \mathrm{C}$-RPBG, $\mathrm{Cl} 250^{\circ} \mathrm{C}$-RPBG, $\mathrm{Cl} 10050^{\circ} \mathrm{C}-\mathrm{RPBG}$ are 84.5, 84.26, 83.98, 83.73, 83.86, 84.19, 84.6 and $83.71 \%$ respectively. VE increases for all PBGs for preheated fuels, this increase in trend for preheated fuel might be because of better atomization and complete combustion [29-32].

Figure 12 (a) \& (b) represents the effect of different PBG's on BSFC for with and without preheated fuels at varying load. Figure 12 (a) refers to the disparity of BSFC results for D-HPBG, Cl 20-HPBG, Cl100-HPBG, D-TPBG, Cl20-TPBG, Cl100-TPBG, D-RPBG, Cl20-RPBG, Cl100-RPBG, and they are noted as 0.26, 0.27, $0.33,0.26$. 0.28. $0.34,0.27,0.29$ and $0.34 \mathrm{~kg} / \mathrm{kWh}$ respectively. Further, for Preheated at $50^{\circ} \mathrm{C}$ fuel [Refer Figure 12(b)], the experimental BSFC of D $50^{\circ} \mathrm{C}-\mathrm{HPBG}, \mathrm{Cl} 2050^{\circ} \mathrm{C}-\mathrm{HPBG}, \mathrm{D} 50^{\circ} \mathrm{C}-\mathrm{TPBG}, \mathrm{Cl} 2050^{\circ} \mathrm{C}-\mathrm{TPBG}$, $\mathrm{Cl} 10050^{\circ} \mathrm{C}-\mathrm{TPBG}, \mathrm{D} 50^{\circ} \mathrm{C}$-RPBG, $\mathrm{Cl} 250^{\circ} \mathrm{C}$-RPBG, $\mathrm{Cl} 10050^{\circ} \mathrm{C}-\mathrm{RPBG}$ are $0.26,0.28,0.26,0.28,0.34$, $0.27,0.28$ and $0.35 \mathrm{~kg} / \mathrm{kWh}$ respectively. It indicates the BSFC of preheated $\mathrm{Cl} 20$ fuel has less for TPBG 
than to other blends and geometry. Due to improved atomization and better fuel was mixing for preheated fuels resulting in the decreased BSFC [29-32].

Figure 13 (a) \& (b) illustrates the Impact of different PBG's on EGT for with and without preheated fuels at varying load. Figure 13(a) gives the disparity of EGT results for D-HPBG, Cl 20-HPBG, Cl100-HPBG, DTPBG, Cl20-TPBG, Cl100-TPBG, D-RPBG, Cl20-RPBG, Cl100-RPBG, and they are noted as 409.46, 424.8, $413.6,407.49,390.2,387.74,411.13,417.6$ and $41.41^{\circ} \mathrm{C}$ respectively. Further, for Preheated at $50^{\circ} \mathrm{C}$ fuel [Refer Figure 13(b)], the experimental EGT of D $50^{\circ} \mathrm{C}-\mathrm{HPBG}, \mathrm{Cl} 2050^{\circ} \mathrm{C}-\mathrm{HPBG}, \mathrm{D} 50^{\circ} \mathrm{C}-\mathrm{TPBG}, \mathrm{Cl} 2050^{\circ} \mathrm{C}$ TPBG, $\mathrm{Cl} 10050^{\circ} \mathrm{C}-\mathrm{TPBG}, \mathrm{D} 50^{\circ} \mathrm{C}$-RPBG, $\mathrm{Cl} 250^{\circ} \mathrm{C}$-RPBG, $\mathrm{Cl} 10050^{\circ} \mathrm{C}-\mathrm{RPBG}$ are $378.35,376.38,395.4$, $390.1,387.74,411.05,404.24$ and $411.05^{\circ} \mathrm{C}$ respectively. It has been noticed that for TPBG the EGT is less than that of other geometries at preheated conditions. This might be due to improved combustion, and better atomization of fuel particles results in the lower EGT [29-32].

\subsection{Influence of Split and Re-Entrant Type Piston Bowl Geometry with diesel and Cl20 biodiesel (with and without preheated) on Engine exhaust emissions.}

The variation of $\mathrm{CO}$ emission with and without preheating for different PBGs are depicted in Figure 14 (a) \& (b). The maximum CO emission at full load without preheating for D-HPBG, CI 20-HPBG, Cl100-HPBG, DTPBG, Cl20-TPBG, Cl100-TPBG, D-RPBG, Cl20-RPBG, Cl100-RPBG are $0.257 \%, 0.241 \%, 0.157 \%, 0.684 \%$, $0.465 \%, 0.461 \%, 1.152 \%$ and $1.127 \%$ and $1.024 \%$ respectively [Refer Figure 14 (a)]. The results show that $\mathrm{CO}$ emission is maximum at full load for D-TPBG and is lowest for Cl20-HPBG. Thus indicating biodiesel helps in the reduction of emission of $\mathrm{CO}$. The emission of $\mathrm{CO}$ for biodiesel blends is slightly lesser than conventional diesel. The reduction in emission of $\mathrm{CO}$ for biodiesel blends is due to the higher oxygen content of biodiesel that will help in complete oxidation combustion. In this study, observed that at lower load, $\mathrm{CO}$ emissions are considerably less compared to the higher load emissions. Because increasing load will increase the gas's in-cylinder temperature, thus resulting in the increased $\mathrm{CO}$ emission. Then for modified geometries, it is seen that they have higher $\mathrm{CO}$ emissions with calophyllum inophyllum biodiesel, which is quite interesting as normally modified geometries are expected to reduce the emission of $\mathrm{CO}$, with better air-fuel movement. Modified PBGs will have better turbulence and squish than the standard diesel engine. Still, $\mathrm{CO}$ emissions can sometimes be unpredictable as many minor aspects determine it depending on the biodiesel and geometry.

The maximum $\mathrm{CO}$ emission at full load with preheating at $50^{\circ} \mathrm{C}$ for $\mathrm{D} 50^{\circ} \mathrm{C}-\mathrm{HPBG}, \mathrm{Cl} 2050^{\circ} \mathrm{C}-\mathrm{HPBG}, \mathrm{D}$ $50^{\circ} \mathrm{C}$-TPBG, $\mathrm{Cl} 2050^{\circ} \mathrm{C}-\mathrm{TPBG}, \mathrm{Cl} 10050^{\circ} \mathrm{C}-\mathrm{TPBG}, \mathrm{D} 50^{\circ} \mathrm{C}-\mathrm{RPBG}, \mathrm{Cl} 250^{\circ} \mathrm{C}-\mathrm{RPBG}, \mathrm{Cl} 10050^{\circ} \mathrm{C}-\mathrm{RPBG}$ are $0.168 \%, 0.216 \%, 0.609 \%, 0.487 \%, 0.475 \%, 0.951 \%, 0.864 \%$ and $1.029 \%$ respectively [Refer Figure 14 (b)]. It is seen from the results that CO emission is maximum at full load for D- $50^{\circ} \mathrm{C}$ TPBG and is lowest for D$50^{\circ} \mathrm{C}$ HPBG. Preheating pure diesel will reduce $\mathrm{CO}$ emissions compared to diesel at room temperature 
even though the reduction in $\mathrm{CO}$ is almost the same as the diesel at room temperature in the case of TPBG. But it has been observed a considerable amount of reduction in CO in HPBG and RPBG with preheating. This may be due to the better combustion and oxidation of diesel, as it is heated before getting inducted into the engine. The same trend is observed for the $\mathrm{Cl} 20$ blend preheated in comparison to the $\mathrm{Cl} 20$ blend without preheating. The study outcomes show that the emission of $\mathrm{CO}$ for biodiesel blends is slightly lesser than conventional diesel [29-32].

Figure 15 (a) \& (b) illustrates the impact of different PBG's on HC emission for with and without preheated fuels at varying load conditions. The maximum $\mathrm{HC}$ emission at full load without preheating for D-HPBG, Cl 20-HPBG, Cl100-HPBG, D-TPBG, Cl20-TPBG, Cl100-TPBG, D-RPBG, Cl20-RPBG, Cl100-RPBG are $98,82,112,41,38,43,42,39$, and $41 \mathrm{ppm}$, respectively. It is seen that $\mathrm{HC}$ emission is maximum at full load for D-HPBG and is lowest for Cl20-TPBG. The standard diesel engine emits the maximum amount of $\mathrm{HC}$ compared to the others. From Figure 15 (a), it was observed that the emission of $\mathrm{HC}$ for biodiesel blends goes on increasing with increased load. Because oxygen availability is bare minimum at higher loads, it was clearly indicated that modified PBGs produce less HC emission than Standard PBG. Because the better air turbulence and enhanced mixture formation in modified PBGs will reduce the $\mathrm{HC}$ emission considerably. The maximum $\mathrm{HC}$ emission at full load with preheating at $50^{\circ} \mathrm{C}$ for $\mathrm{D} 50^{\circ} \mathrm{C}-\mathrm{HPBG}, \mathrm{Cl} 20$ $50^{\circ} \mathrm{C}$-HPBG, D $50^{\circ} \mathrm{C}$-TPBG, $\mathrm{Cl} 2050^{\circ} \mathrm{C}$-TPBG, Cl $10050^{\circ} \mathrm{C}$-TPBG, D 50 ${ }^{\circ} \mathrm{C}$-RPBG, $\mathrm{Cl} 250^{\circ} \mathrm{C}$-RPBG, $\mathrm{Cl} 100$ $50^{\circ} \mathrm{C}-\mathrm{RPBG}$ are $26,39,40,24,23,40,36,16$ and 39ppm respectively. Figure 15 (b) shows that $\mathrm{HC}$ emission is maximum at full load for $\mathrm{Cl} 20-50^{\circ} \mathrm{C} \mathrm{HPBG}$ and is lowest for $\mathrm{Cl} 20-50^{\circ} \mathrm{C}$ TPBG. It is clear that the preheating emission of $\mathrm{HC}$ reduces considerably for a standard diesel engine. Further, with preheating, it was noted that HC's emission is reduced considerably for preheated diesel compared to the diesel at room temperature. Preheating ensures proper combustion; hence it is seen that the $\mathrm{HC}$ emissions were reduced. Even the Biodiesel blends follow the same trend compared to the biodiesel at room temperature. $\mathrm{Cl} 20-50^{\circ} \mathrm{C}$ TPBG has the lowest $\mathrm{HC}$ emission due to the modified geometry that ensures proper air-fuel movement [29-32].

Figure 16 (a) \& (b) indicates the influence of different PBG's on $\mathrm{CO}_{2}$ emission for with and without preheated fuels at varying load conditions. From Figure 16(a), it can be seen that the maximum $\mathrm{CO}_{2}$ emission at full load without preheating for D-HPBG, Cl 20-HPBG, Cl100-HPBG, D-TPBG, Cl20-TPBG, Cl100-TPBG, D-RPBG, Cl20-RPBG, Cl100-RPBG are 10.3, 9.89, 10.6, 10.6, 10.6, 9.94,10.3, 11, 11.2 and $11.5 \%$ respectively. It shows that $\mathrm{CO}_{2}$ emission is maximum for CI20-RPBG and least for Cl20-HPBG at full load. The emission of $\mathrm{CO}_{2}$ goes on increasing for the increasing loads both for biodiesel blends and conventional fuel. It happening due to the limited availability of $\mathrm{O}_{2}$ content as load increases. All the biodiesel blends with different PBGs have almost the same $\mathrm{CO}_{2}$ emission, indicating that the geometry modification doesn't affect much on $\mathrm{CO}_{2}$ emission. The same trend is observed for pure diesel with different PBGs. The $\mathrm{CO}_{2}$ emissions for different biodiesel blends to varying loads with preheating at $50^{\circ} \mathrm{C}$ are illustrated in Figure 16 (b). It has been inferred that the preheated biodiesel blends $\mathrm{D} 50^{\circ} \mathrm{C}-\mathrm{HPBG}, \mathrm{Cl} 20$ $50^{\circ} \mathrm{C}-\mathrm{HPBG}, \mathrm{D} 50^{\circ} \mathrm{C}-\mathrm{TPBG}, \mathrm{Cl} 2050^{\circ} \mathrm{C}-\mathrm{TPBG}, \mathrm{Cl} 10050^{\circ} \mathrm{C}-\mathrm{TPBG}, \mathrm{D} 50^{\circ} \mathrm{C}-\mathrm{RPBG}, \mathrm{Cl} 250^{\circ} \mathrm{C}$-RPBG, $\mathrm{Cl} 100$ 
$50^{\circ} \mathrm{C}-\mathrm{RPBG}$ at maximum load gave $10.0,10.2,10.2,10.0,10.4,10.7,10.5$ and $11.3 \%$ of $\mathrm{CO}_{2}$ emission respectively. It shows that $\mathrm{CO}_{2}$ emission is maximum for D-RPBG $50^{\circ} \mathrm{C}$ and least for B20-TPBG $50^{\circ} \mathrm{C}$ at full load. Even with preheating, there is no considerable change in the emission of $\mathrm{CO}_{2}$ in both biodiesel blends and pure diesel compared to the fuels at room temperature. This might be due to the carbon content present in the fuel that has to be oxidized to $\mathrm{CO}_{2}$. So it is clear that there are no considerable changes in the $\mathrm{CO}_{2}$ emission using different PBGs [29-32].

The variation of $\mathrm{O}_{2}$ emission with and without preheated fuel blends for different PBGs are depicted in Figure 17 (a) \& (b). From Figure 17 (a), it can be seen that the biodiesel blends D-HPBG, Cl 20-HPBG, Cl100-HPBG, D-TPBG, Cl20-TPBG, Cl100-TPBG, D-RPBG, Cl20-RPBG, Cl100-RPBG are at maximum load gave $5.69,5.73,6.07,5.61,6.27,6.26,4.73,4.97$ and $5.23 \%$ of $\mathrm{O}_{2}$ emission respectively. It shows that $\mathrm{O}_{2}$ emission is maximum for Cl20-TPBG and least for D-RPBG at full load. When there is no load applied, the $\mathrm{O}_{2}$ content is at its peak, but with applied loads, the $\mathrm{O}_{2}$ content decreases as $\mathrm{O}_{2}$ is consumed in converting $\mathrm{CO}$ to $\mathrm{CO}_{2}$. Thus the presence of more $\mathrm{O}_{2}$ content is beneficial. And it is seen that the biodiesel blends have more $\mathrm{O}_{2}$ content present than compared with diesel, which makes biodiesel a better fuel to be consumed. And in these biodiesel blends, the toroidal piston bowl geometry (TPBG) has more $\mathrm{O}_{2}$ content available for further utilization. The $\mathrm{O}_{2}$ emissions for different biodiesel blends to varying loads with preheating at $500 \mathrm{C}$ are illustrated in Figure $17(\mathrm{~b})$. From the outcomes of the results, it can be seen that the preheated biodiesel blends D $50^{\circ} \mathrm{C}-\mathrm{HPBG}, \mathrm{Cl} 2050^{\circ} \mathrm{C}-\mathrm{HPBG}, \mathrm{D} 50^{\circ} \mathrm{C}-\mathrm{TPBG}, \mathrm{Cl} 2050^{\circ} \mathrm{C}-\mathrm{TPBG}$, $\mathrm{Cl} 10050^{\circ} \mathrm{C}-\mathrm{TPBG}, \mathrm{D} 50^{\circ} \mathrm{C}-\mathrm{RPBG}, \mathrm{Cl} 250^{\circ} \mathrm{C}-\mathrm{RPBG}, \mathrm{Cl} 10050^{\circ} \mathrm{C}-\mathrm{RPBG}$ at maximum load gave $7.02,6.59$, $5.92,6.24,6.19,4.99,5.65$ and $5.27 \%$ of $\mathrm{O}_{2}$ emission respectively. It shows that $\mathrm{O}_{2}$ emission is maximum for D-HPBG $50^{\circ} \mathrm{C}$ and least for D-RPBG $50^{\circ} \mathrm{C}$ at full load. Heating the biodiesel blends and diesel at $50^{\circ} \mathrm{C}$ before inducing it into the engine results in better oxygen emission, and less $\mathrm{CO}$ is produced as the reaction takes place faster when preheated. Though $\mathrm{CO}_{2}$ and $\mathrm{NO}_{\mathrm{x}}$ consumption also increased, it can be reduced by processes and improving emission characteristics. Even here, biodiesel blends have more oxygen content than diesel blends, giving more fuel consumption [29-32].

The disparity of $\mathrm{NO}_{\mathrm{x}}$ emission with and without preheated fuels for different PBGs are depicted in Figure 18 (a) and (b). The maximum $\mathrm{NO}_{\mathrm{x}}$ emission at full load without preheating for $\mathrm{D}$ and $\mathrm{Cl} 20$ blends with different PBGs are 1655, 1623,1703, 889, 907, 899, 831, 816, and 853ppm for D-HPBG, Cl 20-HPBG, Cl100-HPBG, D-TPBG, Cl20-TPBG, Cl100-TPBG, D-RPBG, Cl20-RPBG, Cl100-RPBG respectively. The results show that $\mathrm{NO}_{\mathrm{x}}$ emission is maximum at full load for D-HPBG and is lowest for Cl20-RPBG. The standard diesel engine emits the maximum amount of $\mathrm{NO}_{\mathrm{x}}$ compared to the others. $\mathrm{NO}_{\mathrm{x}}$ is formed due to the reaction of oxygen and nitrogen in the chamber. Thus the more oxygen, the more is the $\mathrm{NO}_{\mathrm{x}}$ formation. But $\mathrm{NO}_{\mathrm{x}}$ formation is less for Re-entrant piston bowl geometry (RPBG) when compared to the other two geometries. Because the swirling action in re-entrant helps the reaction to reduce and thus biodiesel, the re-entrant (Cl20-RPBG) is the most efficient for reducing emission for $\mathrm{NO}_{x}$. The maximum $\mathrm{NO}_{x}$ emission at full load with preheating for diesel and Cl20 blends with different PBGs are 1325, 1307, 876, 916,899, 
880 and 839 and $841 \mathrm{ppm}$ for D50 ${ }^{\circ} \mathrm{C}-\mathrm{HPBG}, \mathrm{Cl} 2050^{\circ} \mathrm{C}-\mathrm{HPBG}, \mathrm{D} 50^{\circ} \mathrm{C}-\mathrm{TPBG}, \mathrm{Cl} 2050^{\circ} \mathrm{C}-\mathrm{TPBG}, \mathrm{Cl} 100$ $50^{\circ} \mathrm{C}-\mathrm{TPBG}, \mathrm{D} 50^{\circ} \mathrm{C}-\mathrm{RPBG}, \mathrm{Cl} 250^{\circ} \mathrm{C}-\mathrm{RPBG}, \mathrm{Cl} 10050^{\circ} \mathrm{C}-\mathrm{RPBG}$ respectively. The $\mathrm{NO}_{x}$ emission is maximum at full load for $\mathrm{D}-50^{\circ} \mathrm{C} \mathrm{HPBG}$ and is lowest for $\mathrm{Cl} 20-50^{\circ} \mathrm{C}$ RPBG. It has been observed that with the preheating, the emission of $\mathrm{NO}_{x}$ reduces considerably for a standard diesel engine. By preheating the biodiesel and diesel blends at $50^{\circ} \mathrm{C}$, the $\mathrm{NO}_{\mathrm{x}}$ formation at maximum load is decreased drastically compared to without preheated blends. This is because, at high temperature, the $\mathrm{O}_{2}$ formation $\mathrm{CO}_{2}$ takes place more when compared to $\mathrm{NO}_{\mathrm{x}}$ formation. Thus, it is a better choice to preheat the fuels for better emission characteristics. The re-entrant piston bowl geometry gives better results at full load than the other two piston bowl geometry. At 75\% load, the toroidal piston bowl geometry shows the least emission, which concludes that the modification in the piston bowl geometry gives better results than the standard geometry [29-32].

Figure 19 (a) \& (b) represents the effect of different PBG's on Opacity for with and without preheated fuels at varying load conditions. The maximum Opacity at full load without preheating for diesel and Cl20 D-HPBG, Cl 20-HPBG, Cl100-HPBG, D-TPBG, Cl20-TPBG, Cl100-TPBG, D-RPBG, Cl20-RPBG, Cl100RPBG, respectively. The results show that Opacity is maximum at full load for D-RPBG and is lowest for Cl20-HPBG. This indicates that the smoke from D-RPBG is highly opaque, and the least amount of light will pass through it. Opacity means how much smoke is liberated at the end of the fuel consumption process. Figure 19 (a) shows that at full load, the modified piston bowl geometry's Opacity is more compared to the standard, but with biodiesel blend, it's comparatively less. Thus, the biodiesel blend of hemispherical piston bowl geometry (HPBG) is best suited for less Opacity. The maximum Opacity at full load with preheating for diesel and $\mathrm{Cl} 20$ blends with different PBGs are 70.8\%, 78.6\%, 88.2\%, 92.3\%, $87.5 \%, 95.2 \%, 93.1 \%$ and $91.8 \%$ D $50^{\circ} \mathrm{C}-\mathrm{HPBG}, \mathrm{Cl} 2050^{\circ} \mathrm{C}-\mathrm{HPBG}, \mathrm{D} 50^{\circ} \mathrm{C}-\mathrm{TPBG}, \mathrm{Cl} 2050^{\circ} \mathrm{C}-\mathrm{TPBG}, \mathrm{Cl} 100$ $50^{\circ} \mathrm{C}-\mathrm{TPBG}, \mathrm{D} 50^{\circ} \mathrm{C}-\mathrm{RPBG}, \mathrm{Cl} 250^{\circ} \mathrm{C}-\mathrm{RPBG}, \mathrm{Cl} 10050^{\circ} \mathrm{C}-\mathrm{RPBG}$ respectively. Figure 19 (b) clarifies that Opacity is maximum at full load for $\mathrm{D}-50^{\circ} \mathrm{C}$ RPBG and is lowest for $\mathrm{D}-50^{\circ} \mathrm{C}$ HPBG. So it is clear that heating has the least effect on Opacity of the fuel. When the biodiesel blend and the diesel blend are heated at $50 \mathrm{oC}$, the reaction and the formation of $\mathrm{CO} 2$ takes place rapidly, and opacity increases. Thus, for preheated biodiesel blends, the Opacity is more, and it is least for diesel hemispherical piston bowl geometry (D-HPBG). It is highest for diesel re-entrant piston bowl geometry (D-RPBG), but overall it is seen that the biodiesel blends have less Opacity when compared to the diesel blends. Thus, giving better emission characteristics [29-32].

\subsection{Influence of Split and Re-Entrant Type Piston Bowl Geometry with diesel and Cl20 biodiesel (with and without preheated) on Combustion attributes.}

The disparity of cylinder pressure with and without preheating fuels for different PBGs is depicted in Figure 20 (a) \& (b) at 100\% engine load. Figure 20 (a) shows that with standard piston bowl geometry, the highest peak is observed, with diesel having a value of 73.67bar compared to $\mathrm{Cl} 20$, which has a value of 72.41 bar. This may be due to diesel having a higher calorific value as compared to Cl20. Also, diesel's lower viscosity compared to $\mathrm{Cl} 20$ leads to better burning of the fuel in the rapid combustion phase. It is 
also observed that $\mathrm{Cl} 20$ RPBG has resulted in the highest cylinder pressure of 74.33 bar followed by diesel RPBG of 74.01 bar. The RPBG has resulted in the most elevated cylinder pressure, resulting from improved air-fuel mixing with RPBG, resulting in effective burning of charge compared to other type PBGs. Figure 20 (b) observed that due to a decrease in biodiesel's bulk modulus and the increase in fuel temperature, the fuel injection was slightly delayed. Short ignition delay at preheated temperature can also be due to early combustion, resulting in a lower peak pressure of 73.92bar for Cl20 RPBG [33-34].

Impact of different PBG's on Cylinder pressure for with and without preheated fuels at $100 \%$ Engine load conditions are portrayed in Figure 21 (a) \& (b). Biodiesel has a higher stickiness, lesser heating value, and lower capriciousness than diesel, which accounts for the more significant diesel pressure rise. The pressure drops progressively after reaching a maximum value during the expansion process. Figure 20 (a) also inferred that the RPBG has the highest rate of pressure rise of $4.52 \mathrm{bar} /$ degree crank angle compared to other piston bowl geometries. This resulted from increased heat conduction to the cylinder wall of the RPBG due to extreme turbulences, which lead to hasty conflagration temperature and pressure rise rate during burning of fuel at full load. This reason also accounts for toroidal piston bowl geometry with a higher pressure rise rate of $4.49 \mathrm{bar} /$ degree crank angle compared to standard piston bowl geometry of $4.22 \mathrm{bar} /$ degree crank angle for diesel. Similarly, for $\mathrm{Cl} 20$, TPBG has a higher pressure rise rate of $4.27 \mathrm{bar} /$ degree crank angle compared to HPBG of $4.06 \mathrm{bar} /$ degree crank angle. From Figure 21(b), it is observed that even with preheating, the pressure rise for diesel is higher as compared to $\mathrm{Cl} 20$. This could account for the highly volatile nature of diesel, which releases more energy per unit crank angle [3334].

Figure 22 (a) \& (b) indicates the influence of different PBG's on Net Heat Release Rate (NHRR) for with and without preheated fuels at $100 \%$ engine load conditions. It is observed that during the ignition delay period, there is a slight negative heat release rate, which is due to the cooling effect of vaporization of the $\mathrm{Cl} 20$ blend and also due to loss of heat from cylinder walls. Diesel has a higher heat release rate than $\mathrm{Cl} 20$ because of its higher calorie content and lower viscidity. The heat release rate in standard HPBG for diesel was $36.66 \mathrm{KJ} /$ degree higher than $\mathrm{Cl} 20$ due to better air-fuel mixing and faster evaporation. Toroidal piston bowl geometry gives the highest heat release rate of $42.14 \mathrm{KJ} /$ degree with diesel than other PBGs. This was due to superior chemical reaction and proper air-fuel mixture during the compression process due to high turbulence leading to effective combustion of charge, increasing the heat conduction through the walls of the cylinder. Figure 22 (b) observed that preheating of working fluids increases the net heat release rate for both diesel and $\mathrm{Cl} 20$. This may be because preheating increases the temperature of working fluid to a higher temperature compared to not preheating, hence causing it to increase the heat release rate. The highest heat release rate is obtained for toroidal piston bowl geometry is 41.73 $\mathrm{KJ} /$ degree for diesel [33-34].

The variation of cumulative heat release rate (CHRR) with and without preheating of fuels for different PBGs are depicted in Figure 23 (a) \& (b) at 100\% engine load. In Standard operating conditions, with hemispherical PBG, it can be seen that the cumulative heat release rate for diesel fuel is higher than that of the $\mathrm{Cl} 20$ blend. This accounts for the higher calorie content and lower viscidity of diesel when 
compared to the $\mathrm{Cl} 20$ blend. Modification of the piston bowl geometry shows the better movement of the fuel inside the chamber. The re-entrant type PBG shows efficient swish swirl movement of air-fuel mixture inside the chamber. When $\mathrm{Cl} 20$ blend is used as a fuel with re-entrant type PBG along with the efficient movement of the air-fuel mixture, more amount of fuel can be drawn, and hence more heat is released. This statement is evident from Figure 23 as the re-entrant type PBG shows the highest cumulative heat release rate, with a value of $1.19 \mathrm{~kJ} /$ crank angle. In toroidal PBG, it results indicate that the cumulative heat release rate of $1.15 \mathrm{~kJ} /$ degree when diesel is used as fuel is higher than the $\mathrm{Cl} 20$ blend gives 1.13 $\mathrm{kJ} /$ degree. Preheating the biodiesel increases the fuel temperature. This resulted in higher cumulative heat release from $1.13 \mathrm{~kJ} /$ degree to $1.17 \mathrm{~kJ} /$ degree in standard operating conditions. In re-entrant PBG, injecting a preheated biodiesel blend has a higher cumulative heat release rate than preheated diesel [3334].

Figure 24 (a) \& (b) exemplifies the influence of different PBG's on Mass Fraction Burned (MFB) for with and without preheated fuels at $100 \%$ engine load. It has been inferred from Figure 24 that the $1^{\circ}$ to $2^{\circ}$ early CA of MFB occurred for both preheated and without preheated fuels at Re-entrant PBG than to standard and Toroidal PBG. This was happening due to the adequate mixing of charge and turbulence in fuel flow with that of other geometry [33-34].

The variation of Ignition Delay with and without preheating of fuels for different PBGs are depicted in Figure 25 (a) \& (b). Ignition delay is the time period between the start of fuel injection and the beginning of combustion. From Figure 25, it is observed that the ignition delay decreases as the load increases. The reason behind this trend is that as the load increases, the heat inside the chamber increases. This heat aids in faster ignition of the air-fuel mixture and reduces the delay period. The results indicated that the ignition delay decreases when biodiesel blends are used instead of diesel. The reason being, biodiesel has a high cetane number and increased oxygen content. Hence, a reduced ignition delay period is observed. In standard operating conditions with hemispherical PBG, the ignition delay for diesel was $14^{\circ} \mathrm{CA}$, whereas for $\mathrm{Cl} 20$ blend, it was $13^{\circ} \mathrm{CA}$. The $14^{\circ} \mathrm{CA}$ ignition delay period for re-entrant PBG was found to be lower than that of toroidal PBG that is $17^{\circ} \mathrm{CA}$. Re-entrant PBG creates higher turbulence in the chamber, which aids in efficiently mixing the air-fuel mixture, leading to less ignition delay. Preheating the working fluids tends to increase their bulk modulus. This accounts for the increased ignition delay when preheated diesel and biodiesel $\mathrm{Cl} 20$ blend is used. The ignition delay for $\mathrm{Cl} 20$ went up from $13^{\circ} \mathrm{CA}$ to $15^{\circ} \mathrm{CA}$. Hence, the results indicated that preheating the working fluids tends to increase the ignition delay period [33-34].

The variation of combustion duration (CD) with and without preheating of fuels for different PBGs are depicted in Figure 26 (a) \& (b). It indicates that the combustion duration increases as the load increases. The reason being, as the load upturns, the amount of fuel entering the chamber enhances, and hence the time taken to burn the fuel increases. Due to the low viscosity of diesel, efficient air-fuel mixing and rapid atomization results in faster combustion. Therefore, the combustion duration of diesel is lesser than the $\mathrm{Cl} 20$ blend. It can be observed that the combustion duration is the highest for hemispherical PBG (standard condition) when compared to toroidal and re-entrant PBGs. The reason accounted is the low 
turbulence, which results in increased combustion duration. The higher turbulence levels and high flame velocity in toroidal PBG can be accounted for the lesser combustion duration. Toroidal PBG accounts for a lesser combustion duration of $14^{\circ} \mathrm{CA}$ when compared to hemispherical PBG has $19^{\circ} \mathrm{CACD}$, and reentrant PBG has $16^{\circ} \mathrm{CA} C D$. Preheating the working fluids lead to decreased combustion duration. The rate of vaporization of working fluids increases on preheating. Due to the increased rate of vaporization of diesel and $\mathrm{Cl} 20$ blend, the fuel's burning period increases. Across all the piston bowl geometries used, preheated diesel and $\mathrm{Cl} 20$ blend have lowered the combustion duration [33-34].

\section{Conclusions}

In the present research, investigations are carried out on modifying engine piston bowl geometry with $\mathrm{Cl} 20$ blend as fuel and comparing it with standard HPBG. Following are some conclusions of the results of the present research:

- There is an improved BTHE in TPBG than those of RPBG values and for $\mathrm{Cl} 20$ blend, the BTHE is almost $4.08 \%$ higher than the RPBG at 100\% engine load on without preheating. $\mathrm{Cl} 20$ gave higher BTHE with that of without preheated fuels for different PBG's.

- The $\mathrm{Cl} 20$ fuel without preheating has approximately $0.32 \%$ higher ITHE for TPBG than the RPBG. The ITHE of preheated $\mathrm{Cl} 20$ fuel has increased by $2.4 \%$ for RPBG than the other PBGs and fuels.

- The $\mathrm{Cl} 20$ fuel has approximately 3.79\% higher ME for TPBG than the RPBG. The ME of preheated $\mathrm{Cl} 20$ fuel has increased by $1.13 \%$ for TPBG than the other PBGs and fuels.

- There is an improved IP in RPBG than those of TPBG values, and for the Cl20 blend, the IP is almost $3.36 \%$ higher than the TPBG at $100 \%$ engine load. Preheated fuels have higher IP than cold fuels for different PBG's.

- The VE of different fuels at various PBG's are 84.33, 82.17, 81.32, 84.08, 84.17, 83.97, 83.58, 84.51 and $83.72 \%$ respectively. From the obtained results, it is seen that VE increased for modified PBGs. Furthermore, for Preheated at $50^{\circ} \mathrm{C}$ fuel the experimental VE 84.5, 84.26, 83.98, 83.73, 83.86, 84.19, 84.6 and $83.71 \%$ respectively. For pre heated and without preheated fuels, VE increase for all PBGs.

- The BSFC of different fuels at various PBG's are $0.26,0.27,0.33,0.26 .0 .28 .0 .34,0.27,0.29$ and 0.34 $\mathrm{kg} / \mathrm{kWh}$ respectively. Further, for Preheated at $50^{\circ} \mathrm{C}$ fuel the experimental BSFC are $0.26,0.28,0.26$, $0.28,0.34,0.27,0.28$ and $0.35 \mathrm{~kg} / \mathrm{kWh}$ respectively. It indicates the BSFC of preheated $\mathrm{Cl} 20$ fuel has less for TPBG than to other blends and geometry.

- The EGT of different fuels at various PBG's are 409.46, 424.8, 413.6, 407.49, 390.2, 387.74, 411.13, 417.6 and $41.41^{\circ} \mathrm{C}$ respectively. Further, for Preheated at $50^{\circ} \mathrm{C}$ fuel the experimental EGT are 378.35 , $376.38,395.4,390.1,387.74,411.05,404.24$ and $411.05^{\circ} \mathrm{C}$ respectively. It has been noticed that for TPBG the EGT is less than that of other geometries at pre heated conditions.

- Cylinder pressure increases by 4\% for RPBG compared to HPBG when $\mathrm{Cl} 20$ blend is used as fuel but decreases by $3.6 \%$ when TPBG is used.

- The rate of pressure rise increases by $5.2 \%$ for TPBG and $8.7 \%$ for RPBG compared to HPBG. 
- The NHRR and CHRR of Cl20 are $11.7 \%$ and $4.4 \%$ for RPBG.

- The ignition delay and combustion duration are decreased by $3.6 \%$ and $4 \%$, respectively, for RPBG.

- $\mathrm{Cl}$ fuel produces lesser emissions than diesel with all PBGs except for preheated Cl fuel with TPBG. This may be due to the more inferior air-fuel movement of preheated $\mathrm{Cl}$ fuel inside TPBG.

- The preheated diesel produces lesser $\mathrm{CO}, \mathrm{HC}$, and NOx emission with all PBGs compared to the diesel at room temperature. Whereas the release of $\mathrm{O}_{2}$ is increased, and $\mathrm{CO}_{2}$ remains almost the same. Thus, Emission characteristics can also be enhanced by preheating the diesel before inducing it into the engine.

- The emission of $\mathrm{HC}, \mathrm{NO}_{x}, \mathrm{CO}_{2}$ increases with increasing load. Because of the availability of oxygen is bare minimum at higher loads. The opacity and $\mathrm{CO}$ emission doesn't follow a linear trend with increasing weight.

Overall, the results indicate that the modified RPBG shows significant performance, combustion, and emission characteristics compared to HPBG and TPBG. Hence, RPBG is a suitable alternative to the existing standard PBG. $\mathrm{Cl} 20$ blend with the modified PBGs has resulted in enhanced engine characteristics. Thus, the RPBG fuelled with $\mathrm{Cl} 20$ blend is a suitable alternative to the conventional $\mathrm{Cl}$ engine PBG.

\section{Declarations}

Ethics approval and consent to participate -Not Applicable

Consent for publication-Not Applicable

Availability of data and materials -Due to the nature of this research, participants of this study did not agree for their data to be shared publicly, so supporting data is not available.

ORCID -Mohan Das A.N https://orcid.org/0000-0003-4670-9077

Competing interests-Not Applicable

Funding-Not Applicable

Authors' contributions- MDAN has conducted the experiments, and a draft copy of the work has been prepared. SHK, GH, BHB, and JTD have analysed the results and illustrated the conclusions. SN has done tabulation of the results, graphs, and CAD model of the devices used in this work.

\section{Acknowledgment}

The authors wish to express their sincere gratitude to Dr. Keshavamurthy R, Professor and Head, Department of Mechanical Engineering, DSCE, management of Dayananda Sagar College of Engineering, 
and Department of Science and Library for their support to complete the research work.

\section{References}

1. Ramadhas, A. ., Jayaraj, S., \& Muraleedharan, C. (2004). Use of vegetable oils as I.C. engine fuels-A review. Renewable Energy, 29(5), 727-742. doi:10.1016/j.renene.2003.09.008

2. Agarwal, D., Kumar, L., \& Agarwal, A. K. (2008). Performance evaluation of a vegetable oil fuelled compression ignition engine. Renewable Energy, 33(6), 1147-

1156. doi:10.1016/j.renene.2007.06.017

3. Selaimia, R., Beghiel, A., \& Oumeddour, R. (2015). The Synthesis of Biodiesel from Vegetable Oil. Procedia - Social and Behavioral Sciences, 195, 1633-1638. doi:10.1016/j.sbspro.2015.06.221

4. Barnard, T. M., Leadbeater, N. E., Boucher, M. B., Stencel, L. M., \& Wilhite, B. A. (2007). ContinuousFlow Preparation of Biodiesel Using Microwave Heating. Energy \& Fuels, 21(3), 17771781. doi:10.1021/ef0606207

5. Knothe, Historical perspectives on vegetable oil-based diesel fuels, Inform 12 (2001) 1103 - 1107.

6. Gharehghani, A., Mirsalim, M., \& Hosseini, R. (2017). Effects of waste fish oil biodiesel on diesel engine combustion characteristics and emission. Renewable Energy, 101, 930936. doi:10.1016/j.renene.2016.09.045

7. Tripathi, S., \& Subramanian, K. A. (2017). Experimental investigation of utilization of Soya soap stock based acid oil biodiesel in an automotive compression ignition engine. Applied Energy, 198, 332346. doi:10.1016/j.apenergy.2017.02.057

8. Lee, S., \& Kim, T. Y. (2017). Performance and emission characteristics of a DI diesel engine operated with diesel/DEE blended fuel. Applied Thermal Engineering, 121, 454461. doi:10.1016/j.applthermaleng.2017.04.112

9. Hoang, A. T. (2019). Experimental study on spray and emission characteristics of a diesel engine fueled with preheated bio-oils and diesel fuel. Energy. doi:10.1016/j.energy.2019.01.076.

10. Kodate, S.V., Yadav, A.K. \& Kumar, G.N. Combustion, performance and emission analysis of preheated KOME biodiesel as an alternate fuel for a diesel engine. J Therm Anal Calorim 141, 23352345 (2020). https://doi.org/10.1007/s10973-020-09814-5.

11. Karthickeyan, V. (2019). Effect of Combustion Chamber Bowl Geometry Modification on Engine Performance, Combustion and Emission characteristics of Biodiesel Fuelled Diesel Engine with its Energy and Exergy Analysis. Energy. doi:10.1016/j.energy.2019.04.012.

12. GANJI, P.R., SINGH, R.N., RAJU, V.R.K. et al. Design of piston bowl geometry for better combustion in direct-injection compression ignition engine. Sādhanā 43, 92 (2018). https://doi.org/10.1007/s12046-018-0907-x.

13. Kattela, S.P., Vysyaraju, R.K.R., Surapaneni, S.R. et al. Effect of n-butanol/diesel blends and piston bowl geometry on combustion and emission characteristics of $\mathrm{Cl}$ engine. Environ Sci Pollut Res 26, 1661-1674 (2019). https://doi.org/10.1007/s11356-018-3704-5 
14. Temizer, İ., \& Cihan, Ö. (2020). Analysis of different combustion chamber geometries using hydrogen / diesel fuel in a diesel engine. Energy Sources, Part A: Recovery, Utilization, and Environmental Effects, 1-18. doi:10.1080/15567036.2020.1811808.

15. Jaichandar, K. Annamalai, Influences of re-entrant combustion chamber geometry on the performance of Pongamia biodiesel in a DI diesel engine, Energy,44(1), ISSN 0360-5442,Pp633-640 (2012), https://doi.org/10.1016/j.energy.2012.05.029.

16. Subramani, L., Venu, H. Evaluation of methyl ester derived from novel Chlorella emersonii as an alternative feedstock for DI diesel engine \& its combustion, performance and tailpipe emissions. Heat Mass Transfer 55, 1513-1534 (2019). https://doi.org/10.1007/s00231-018-2530-0

17. Vedharaj, R. Vallinayagam, W.M. Yang, C.G. Saravanan, P.S. Lee,Optimization of combustion bowl geometry for the operation of kapok biodiesel - Diesel blends in a stationary diesel engine, fuel,139, ISSN 0016-2361, Pp561-567,2015, https://doi.org/10.1016/j.fuel.2014.09.020.

18. Venkata Ramesh Mamilla, M.V. Mallikarjun, G. Lakshmi Narayana Rao, Effect of Combustion Chamber Design on a DI Diesel Engine Fuelled with Jatropha Methyl Esters Blends with Diesel, Procedia Engineering, Volume 64, ISSN 1877-7058, Pages 479-490,2013, https://doi.org/10.1016/j.proeng.2013.09.122.

19. Sankar Ganesh R., Ganesh Babu B. \& Ragupathy Karu(2019)Experimental investigations on direct injection diesel engines using grape seed oil methyl ester with different bowl geometries, International Journal of Green Energy, 16:8, 590-

597, DOI: 1080/15435075.2019.1601095

20. Dilip Kumar Bora , L M Das and M K Gajendra Babu, Performance of a mixed biodiesel fueled diesel engine, Journal of Scientific \& Industrial Research, Vol. 67, January 2008, pp.73-76.

21. Prakash, T., Geo, V.E., Martin, L.J. et al. Evaluation of pine oil blending to improve the combustion of high viscous (castor oil) biofuel compared to castor oil biodiesel in a $\mathrm{Cl}$ engine. Heat Mass Transfer 55, 1491-1501 (2019). https://doi.org/10.1007/s00231-018-2519-8

22. Channappagoudra M, Ramesh K, \& Manavendra G, "Effect of piston bowl geometry on diesel engine performance operated with dairy scum biodiesel", International Journal of Ambient Energy, 117. doi:10.1080/01430750.2018.1525575, 2018.

23. Kumar V, "Experimental investigation of piston bowl geometry effects on performance and emissions characteristics of diesel engine at variable injection pressure and timings", International Journal of Ambient Energy, vol.39(7), pp. 685-693, 2017.

24. Ganji P. R, Singh R. N, Raju V. R. K, \& Srinivasa Rao S, “Design of piston bowl geometry for better combustion in direct-injection compression ignition engine" Sādhanā, 43(6), doi:10.1007/s12046018-0907-x, 2018. .

25. Lalvani J. I. J, Parthasarathy M, Dhinesh B, \& Annamalai K "Experimental investigation of combustion, performance and emission characteristics of a modified piston", Journal of Mechanical Science and Technology, 29(10) 4519-4525, doi:10.1007/s12206-015-0951-y, (2015). 
26. Ramesh Bapu B. R, Saravanakumar, L \& Durga Prasad B, "Effects of combustion chamber geometry on combustion characteristics of a DI diesel engine fueled with calophyllum inophyllum methyl ester", Journal of the Energy Institute, 90(1) 82-100, doi:10.1016/j.joei.2015.10.004, 2017.

27. Varun Singh P, Tiwari S. K, Singh R \& Kumar N, "Modification in combustion chamber geometry of $\mathrm{Cl}$ engines for suitability of biodiesel: A review", Renewable and Sustainable Energy Reviews, 79, 10161033, doi:10.1016/j.rser.2017.05.116, 2017.

28. Mohan Das A.N, Harish G, Jagannatha T.D and Shanmuganatan S.P, “Experimental Investigation and Assessment of Performance and Emission Characteristics of CIME Fuelled Cl Engine", International Journal of Scientific and Engineering Research(IJSER), Vol. 11, Issue 2, 2020, ISSN: 2229-5518, PP 637-648.

29. Zhang, T., Eismark, J., Munch, K., \& Denbratt, I. (2019). Effects of a wave-shaped piston bowl geometry on the performance of heavy duty Diesel engines fueled with alcohols and biodiesel blends. Renewable Energy. doi:10.1016/j.renene.2019.10.057

30. Hazar, H., Sevinc, H., \& Sap, S. (2019). Performance and emission properties of preheated and blended fennel vegetable oil in a coated diesel engine. Fuel, 254, 115677. doi:10.1016/j.fuel.2019.115677

31. Ramakrishnan, M., Rathinam, T. M., \& Viswanathan, K. (2017). Comparative studies on the performance and emissions of a direct injection diesel engine fueled with neem oil and pumpkin seed oil biodiesel with and without fuel preheater. Environmental Science and Pollution Research, 25(5), 4621-4631. doi:10.1007/s11356-017-0838-9

32. Kumar, K. V., Shailesh, P., Raghavan, K. S., Babu, J. A. R., \& Kumar, P. R. (2019). Experimental investigation on performance and emission characteristics of modified piston in DI diesel engine. Australian Journal of Mechanical Engineering, 1-6. doi:10.1080/14484846.2019.1623004

33. Dhinesh, B., Annamalai, M., Lalvani, I. J., \& Annamalai, K. (2017). Studies on the influence of combustion bowl modification for the operation of Cymbopogon flexuosus biofuel based diesel blends in a DI diesel engine. Applied Thermal Engineering, 112, 627637. doi:10.1016/j.applthermaleng.2016.10.117

34. Senthur Prabu, S., Asokan, M. A., Prathiba, S., Ahmed, S., \& Puthean, G. (2018). Effect of additives on performance, combustion and emission behavior of preheated palm oil/diesel blends in DI diesel engine. Renewable Energy, 122, 196-205. doi:10.1016/j.renene.2018.01.068

\section{Figures}




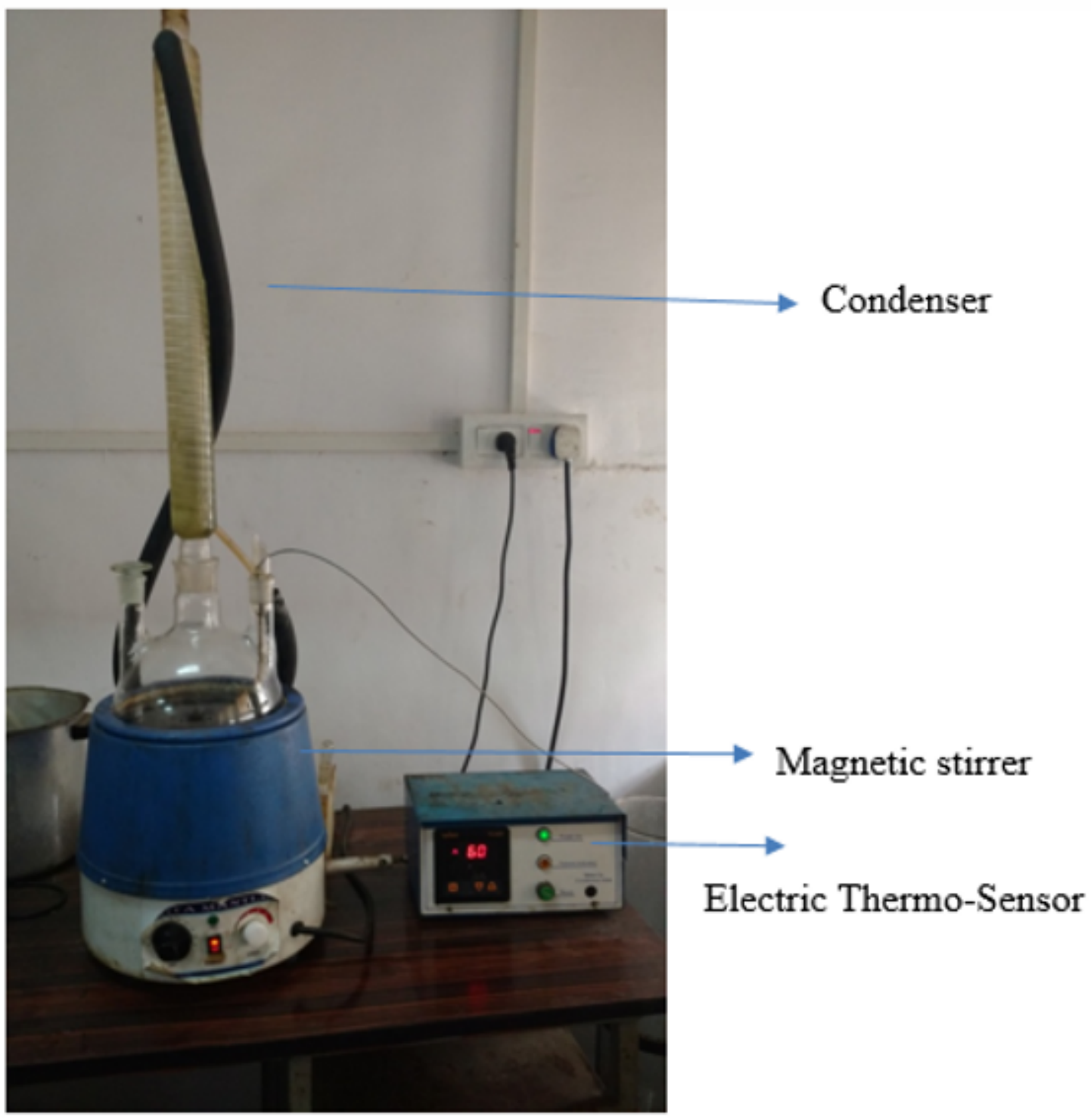

Figure 1

Transesterification process set-up 


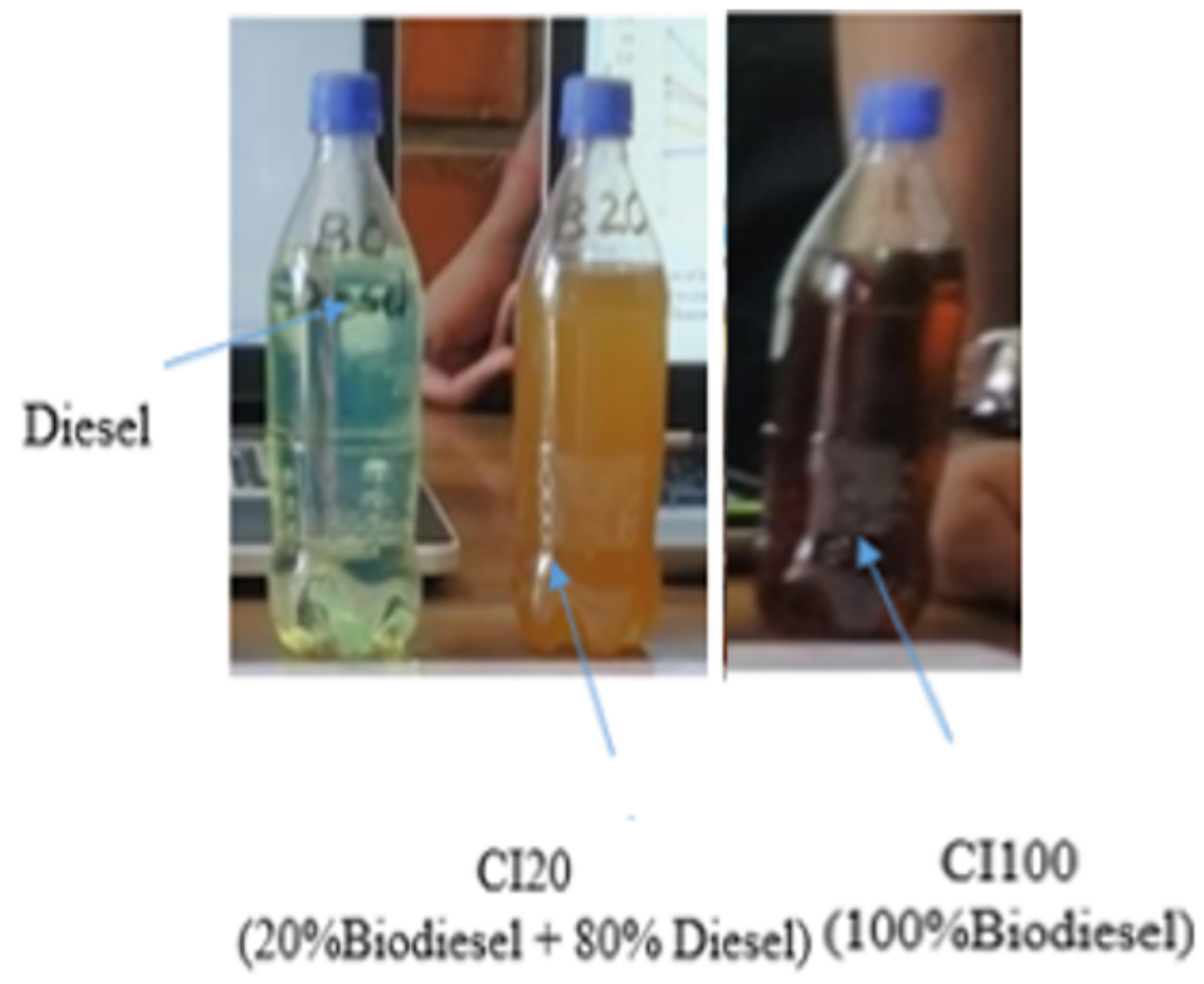

Figure 2

Biodiesel blends
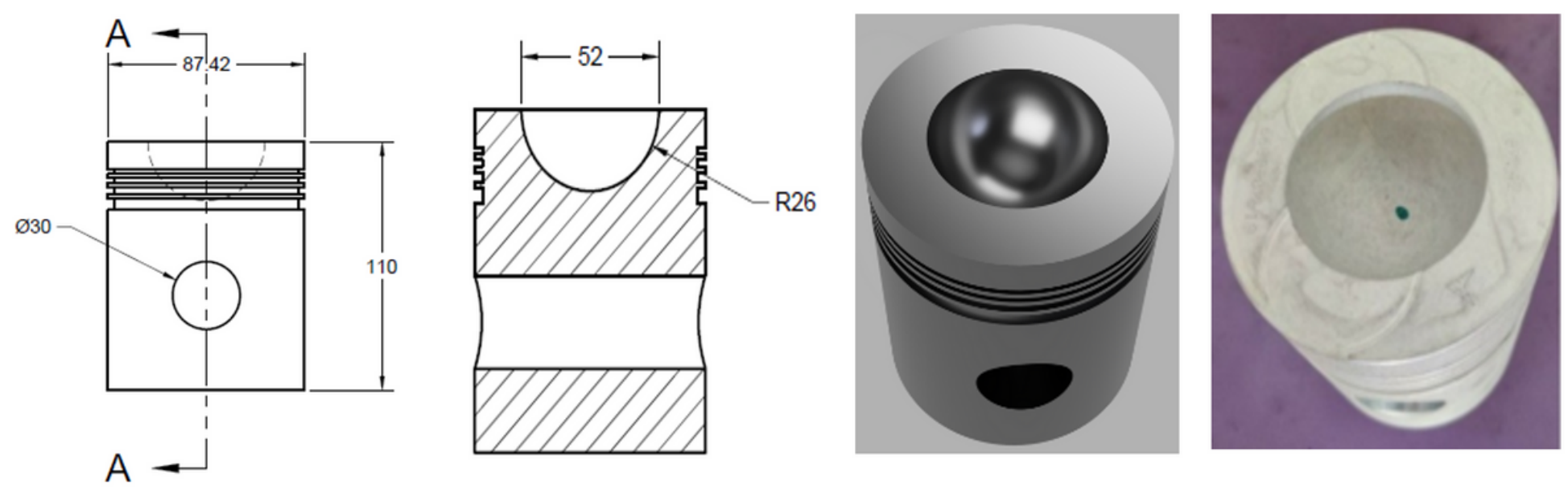

Figure 3

Photographic and CAD model of HPBG 

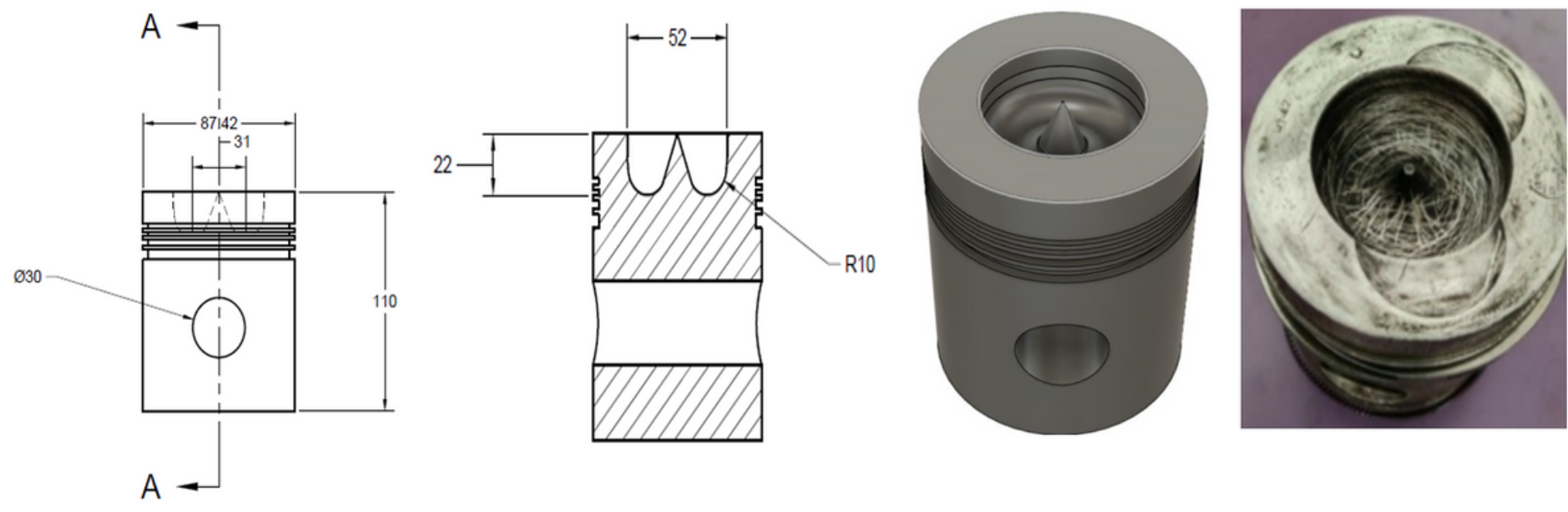

\section{Figure 4}

Photographic and CAD model of TPBG
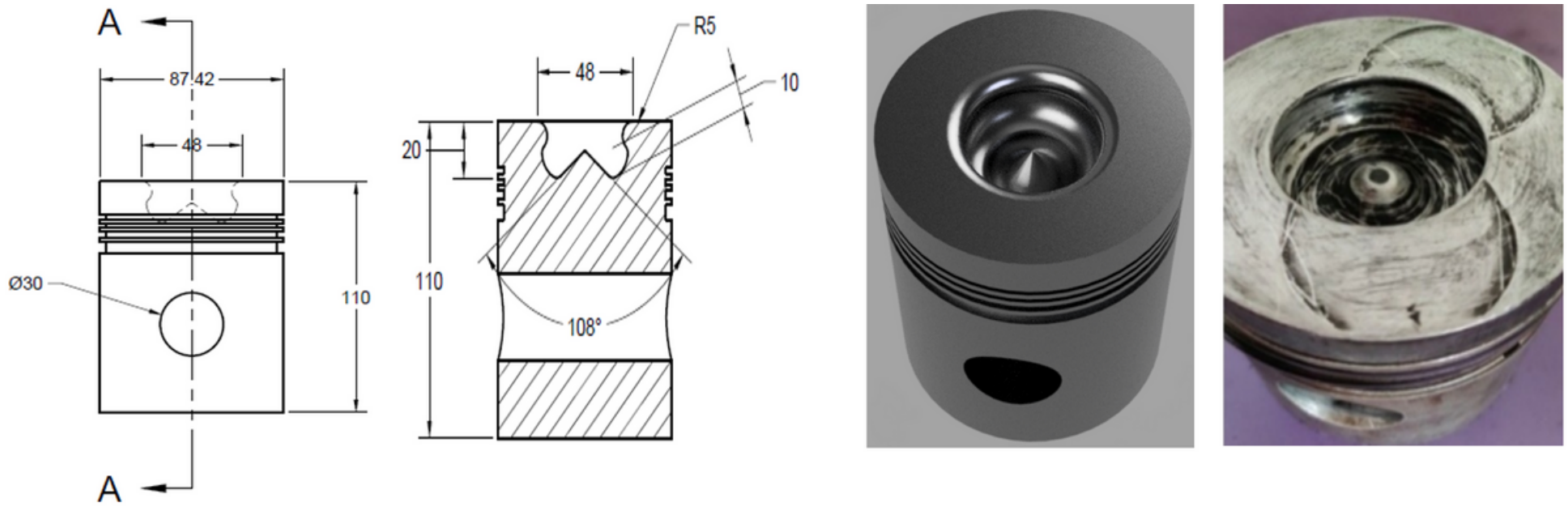

Figure 5

Photographic and CAD model of RPBG 


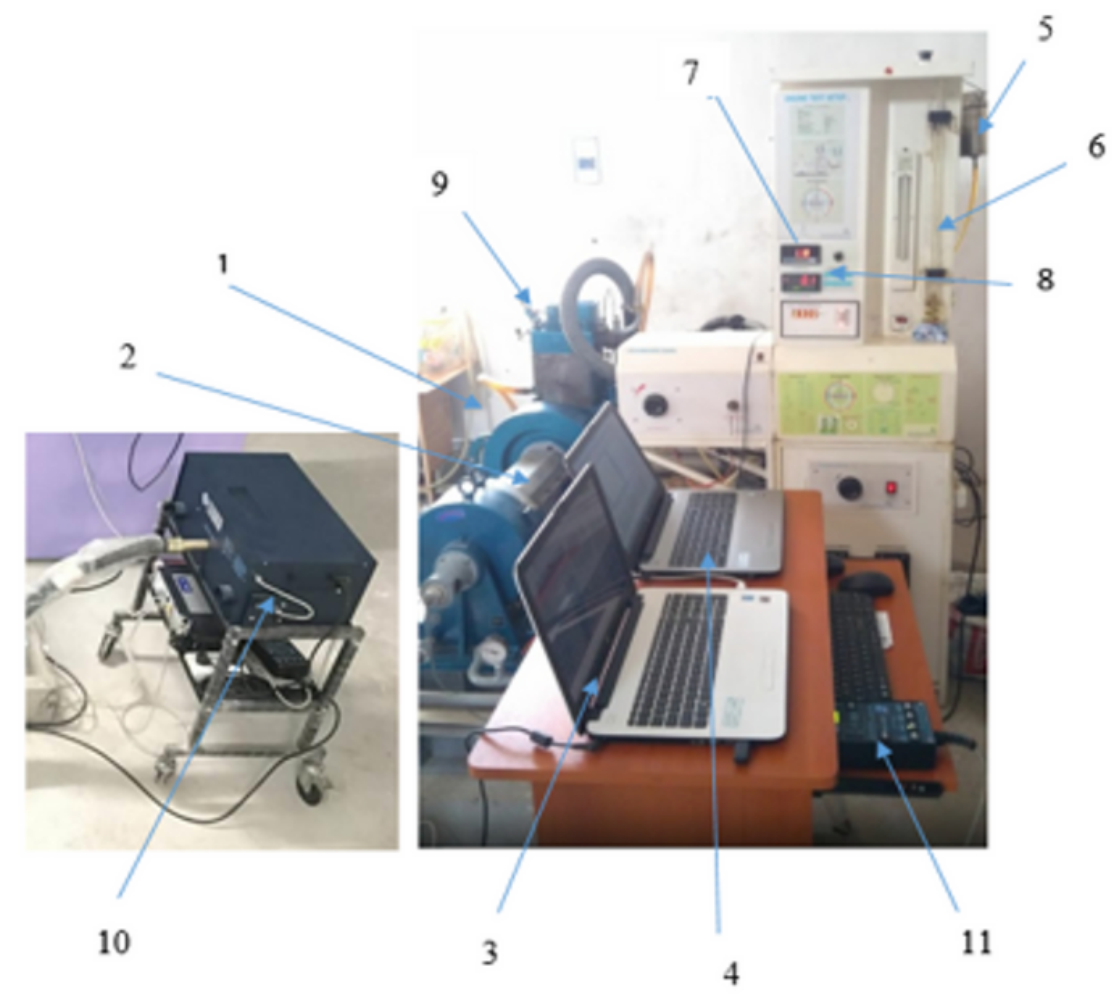

1. Kirloskar Model TV1 single Cylinder Diesel Engine

2. Eddy Current Dynamometer

3. DAQ for Emissions

4. DAQ for Performance and Combustion Characteristics

5. Fuel Tank

6. Burette

7. Electric Load Digital Indicator

8. Mechanical Load Digital Indicator

9. Fuel Injector

10. AVL 5 Gas Analyser

11. Smoke Meter

\section{Figure 6}

An image of engine test rig

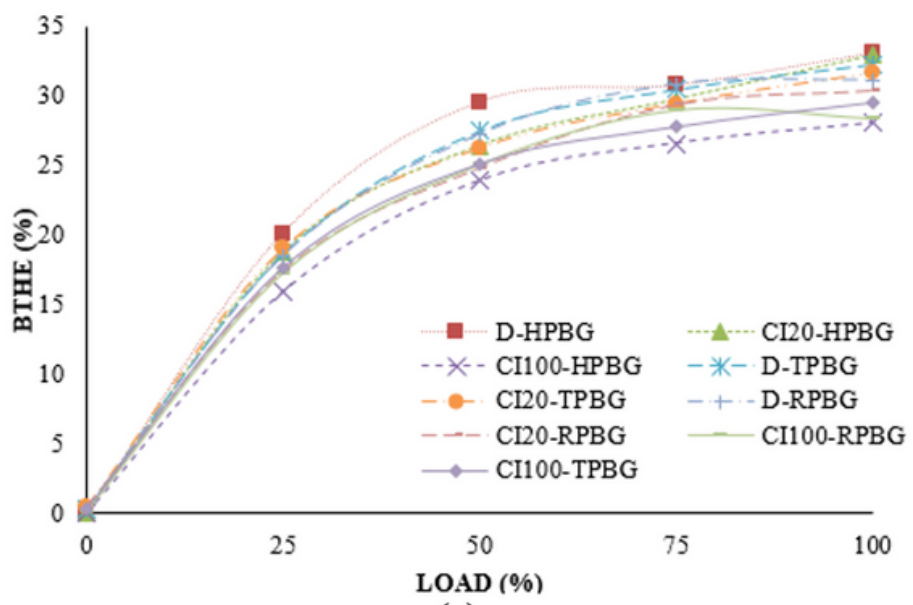

(a)

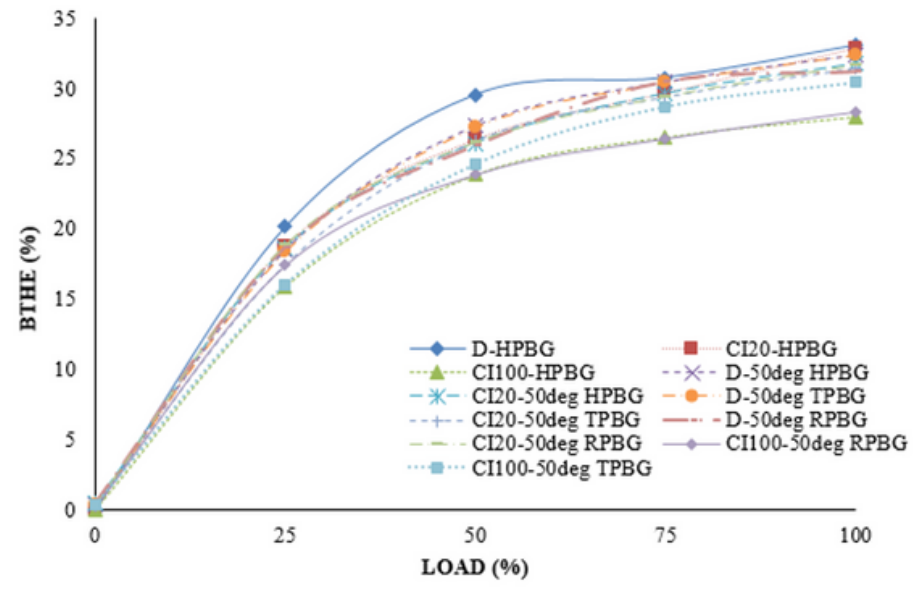

(b)

\section{Figure 7}

Influence of different PBG's on BTHE for with and without preheated fuels at varying load conditions 


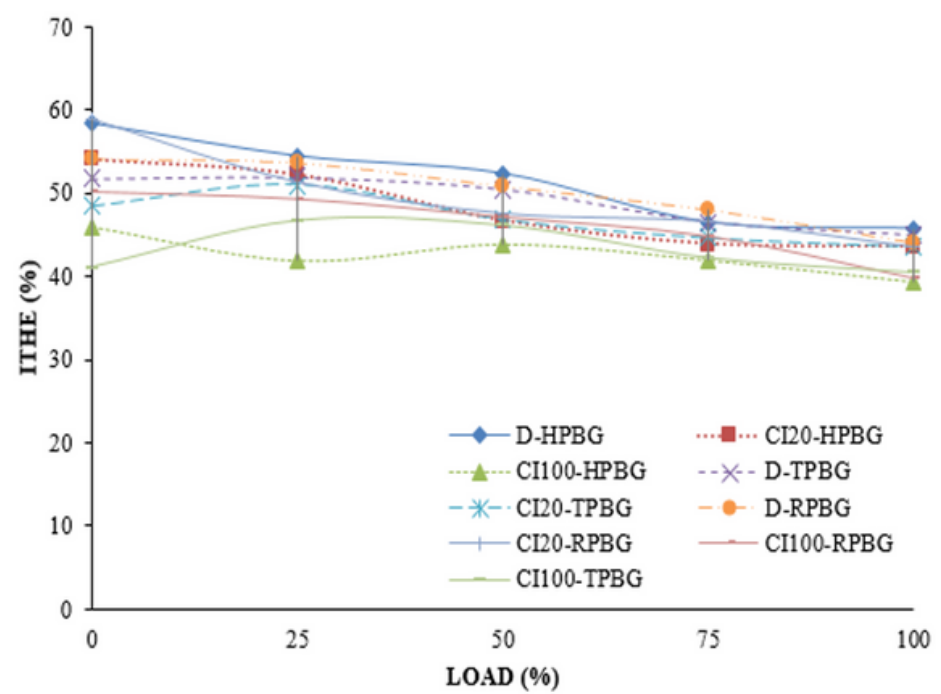

(a)

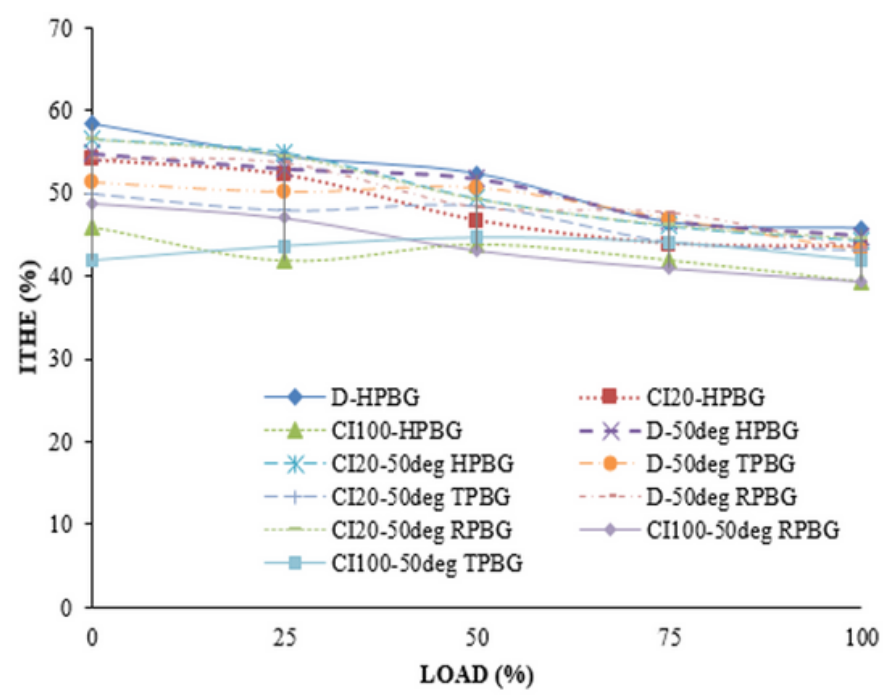

(b)

\section{Figure 8}

Impact of different PBG's on ITHE for with and without preheated fuels at varying load conditions

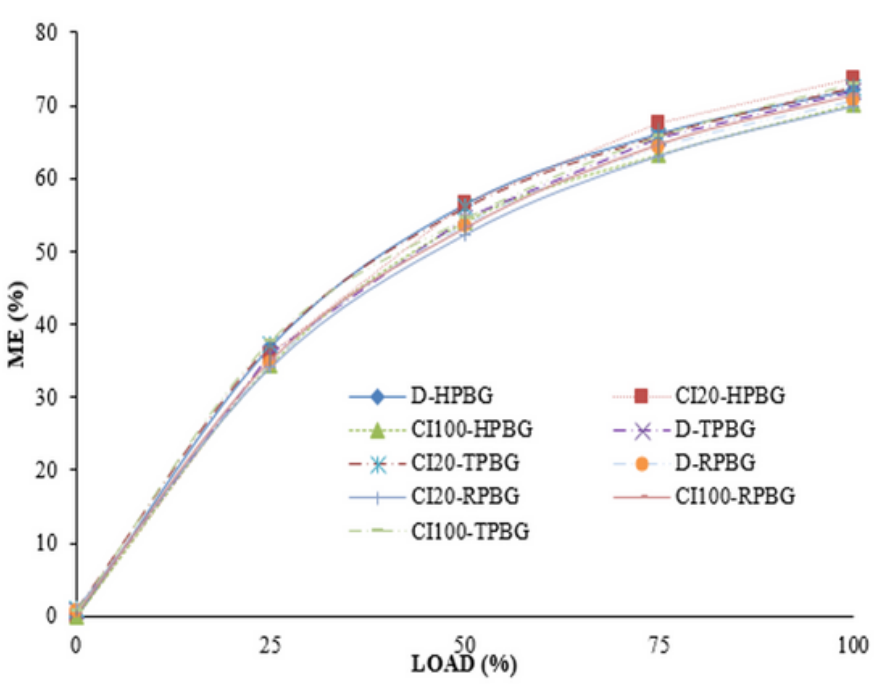

(a)

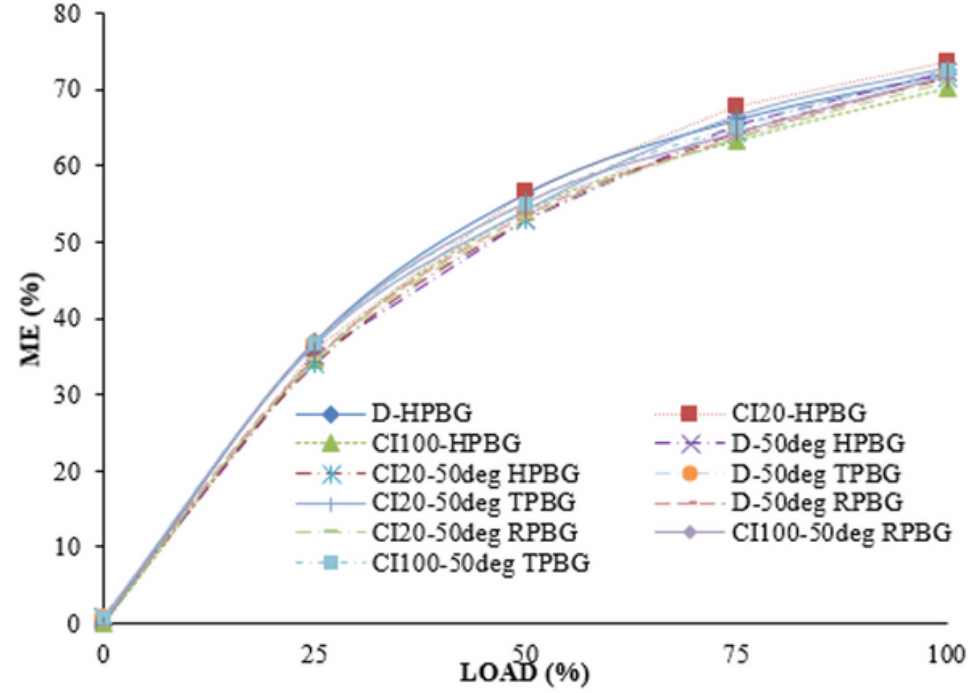

(b)

\section{Figure 9}

Effect of different PBG's on ME for with and without preheated fuels at varying load conditions 


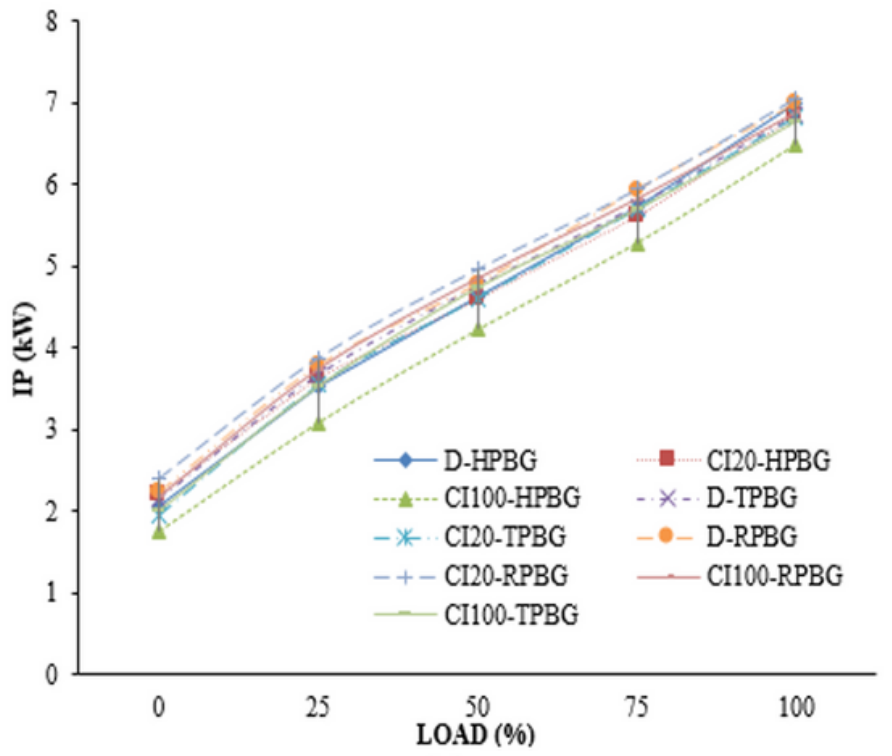

(a)

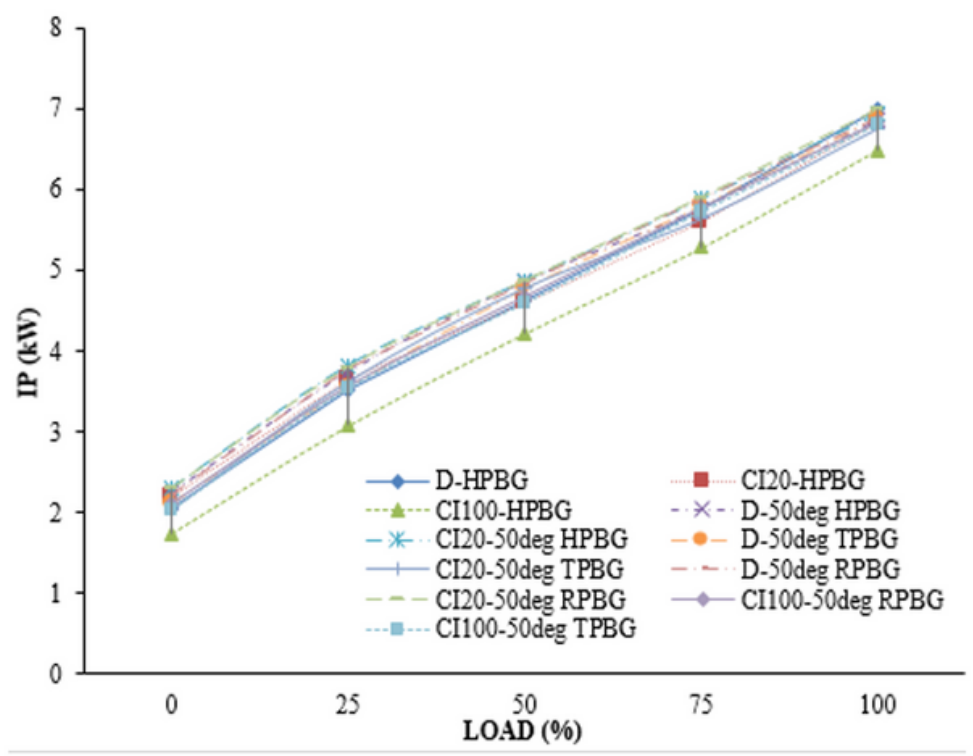

(b)

Figure 10

Influence of different PBG's on IP for with and without preheated fuels at varying load conditions

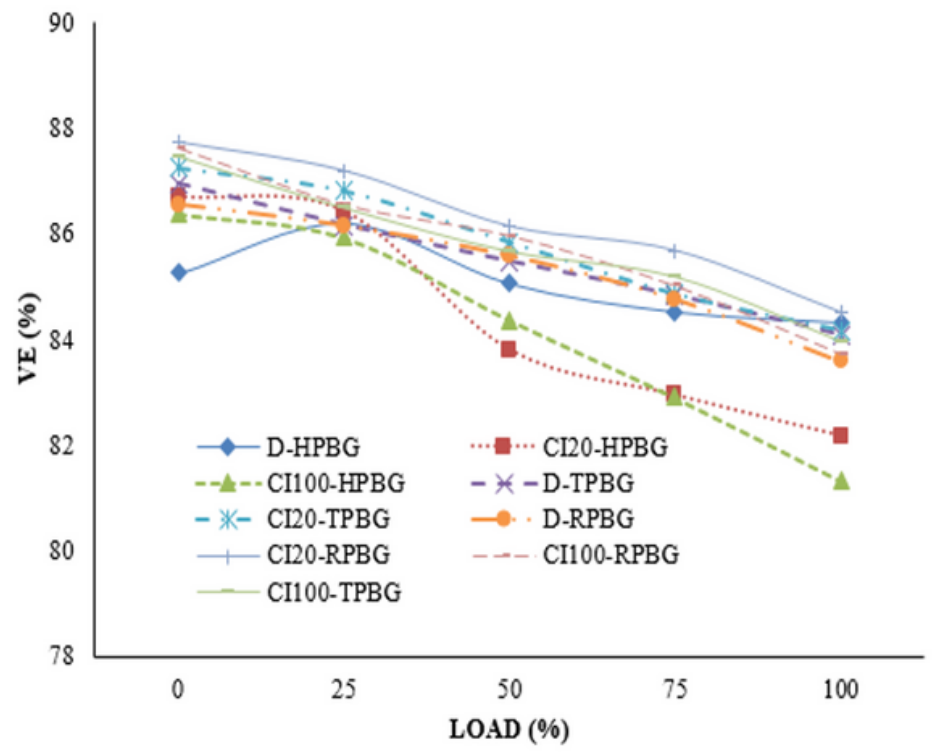

(a)

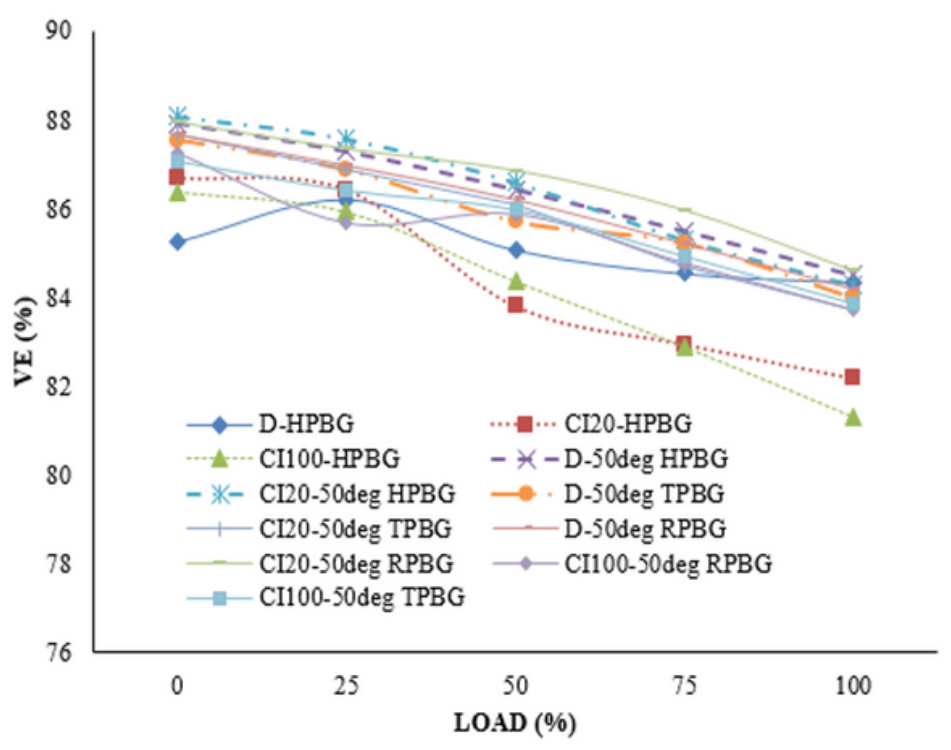

(b)

\section{Figure 11}

Influence of different PBG's on VE for with and without preheated fuels at varying load conditions 


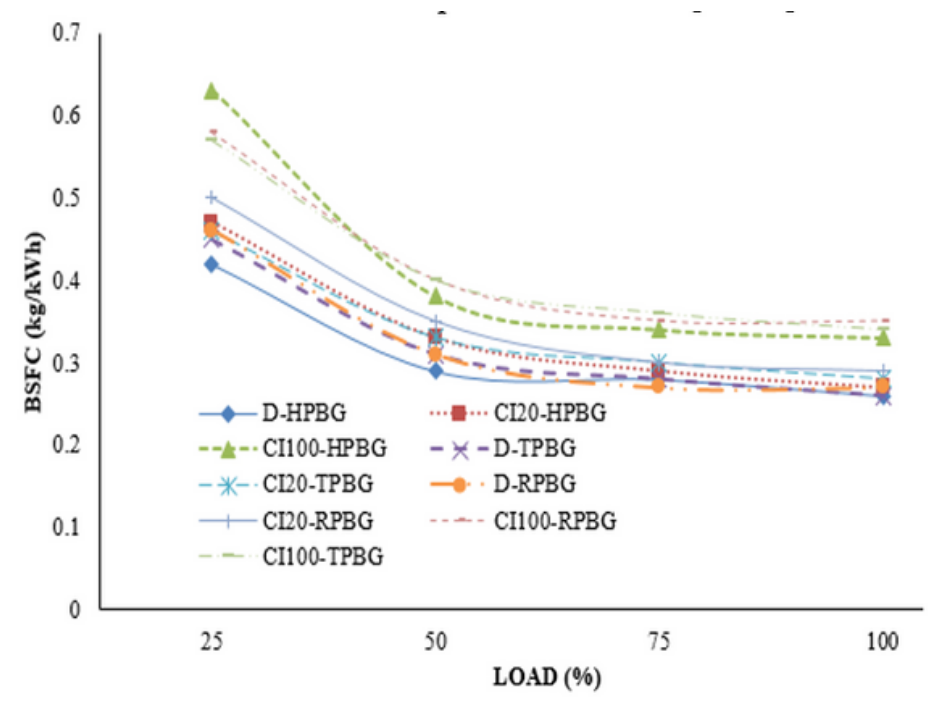

(a)

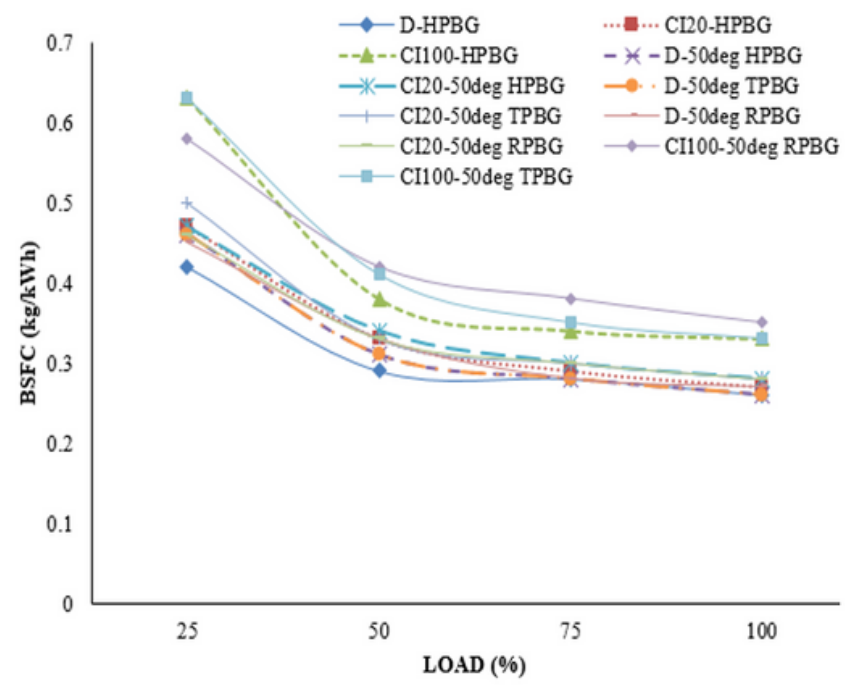

(b)

\section{Figure 12}

Ascendancy of different PBG's on BSFC for with and without preheated fuels at varying load conditions

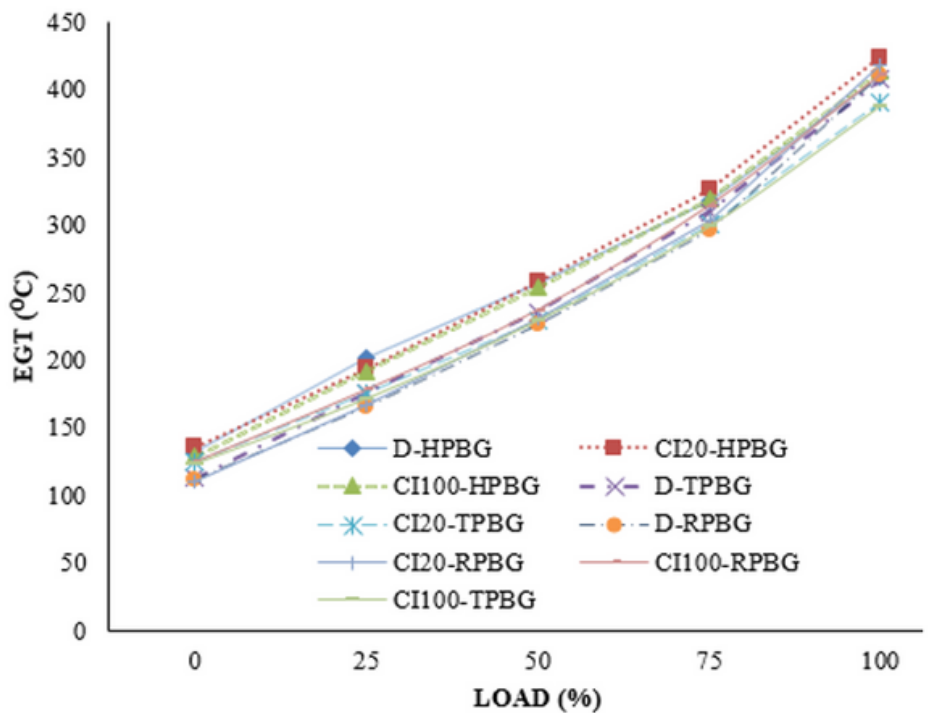

(a)

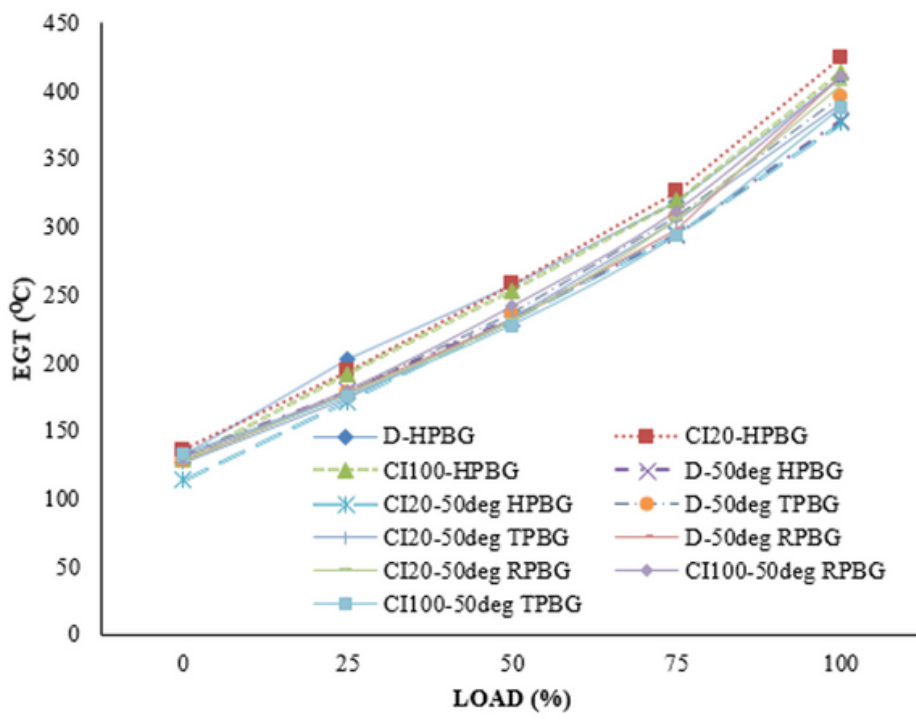

(b)

\section{Figure 13}

Influence of different PBG's on EGT for with and without preheated fuels at varying load conditions 


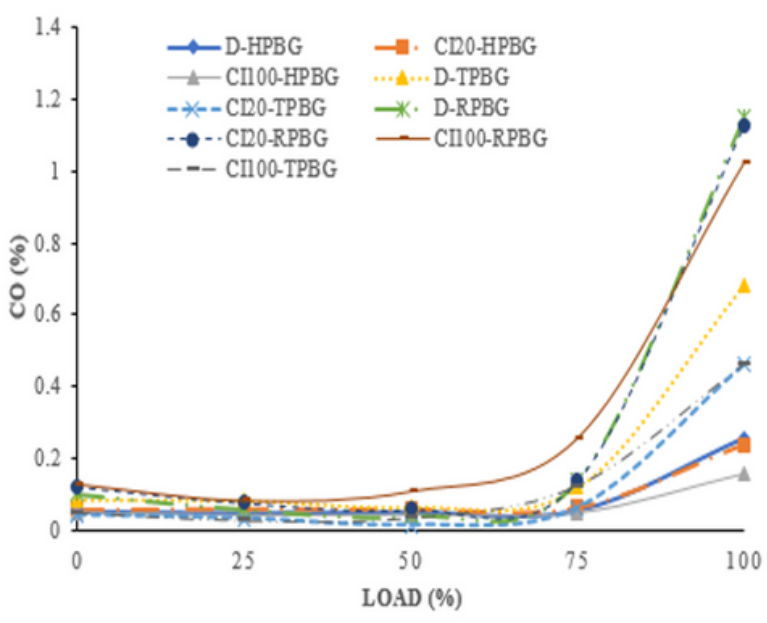

(a)

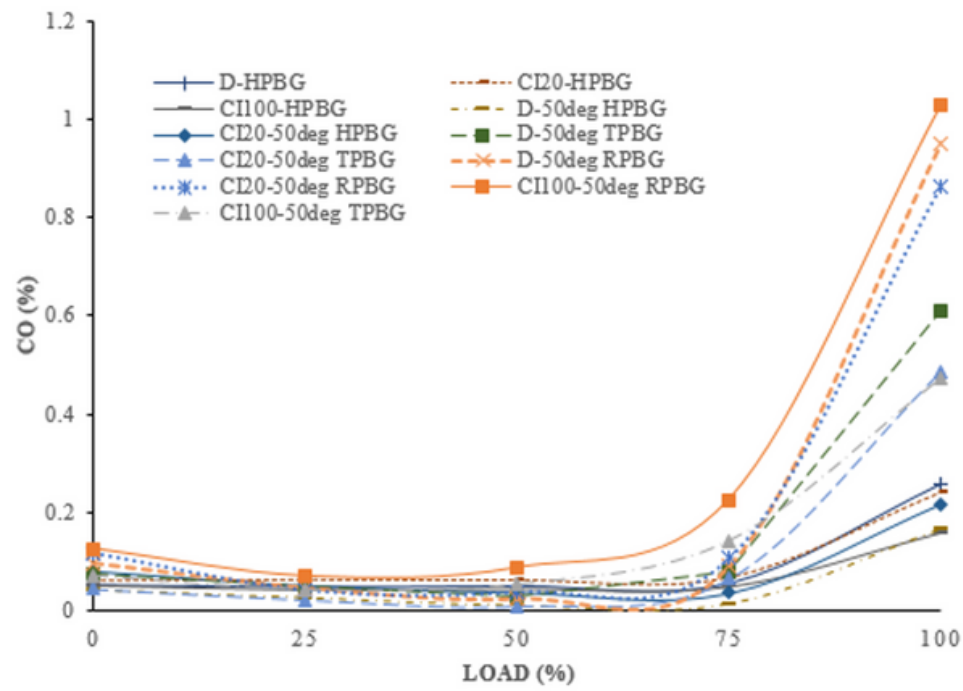

(b)

\section{Figure 14}

Effect of different PBG's on $\mathrm{CO}$ emission for with and without preheated fuels at varying load conditions

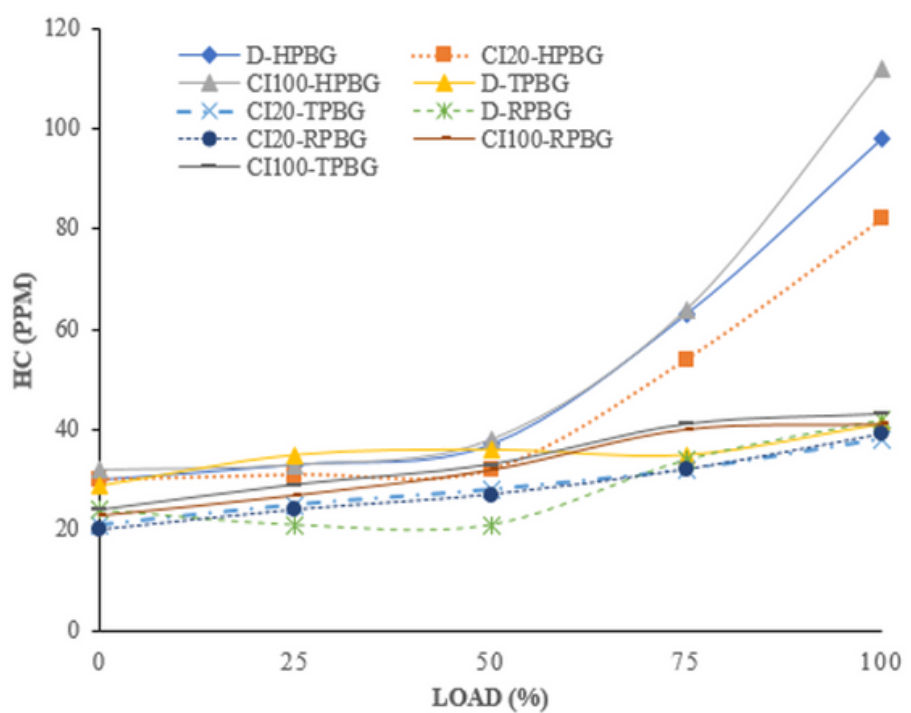

(a)

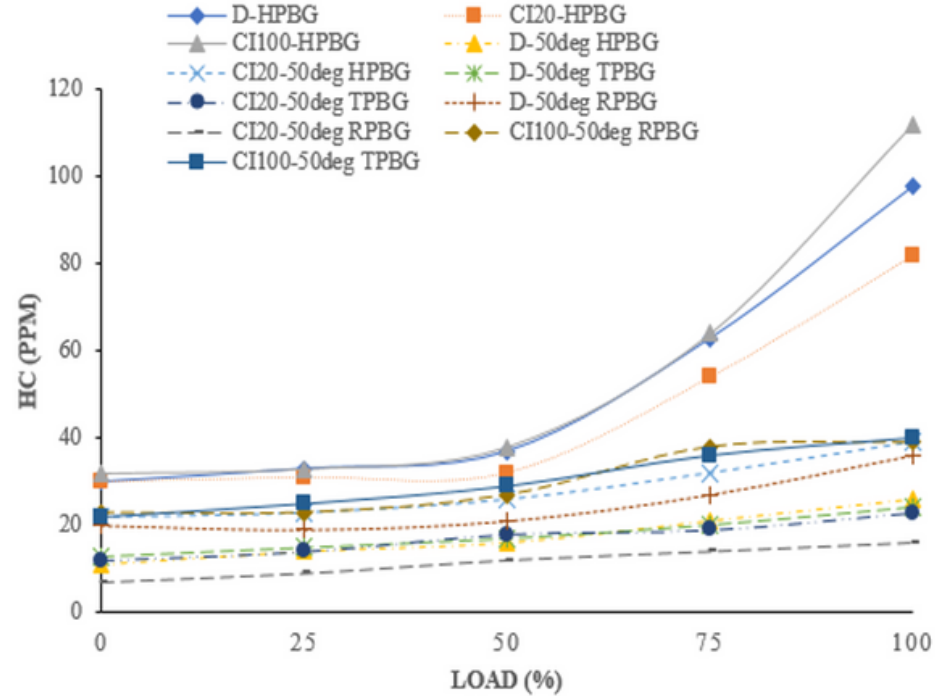

(b)

\section{Figure 15}

Consequences of different PBG's on HC emission for with and without preheated fuels at varying load conditions 


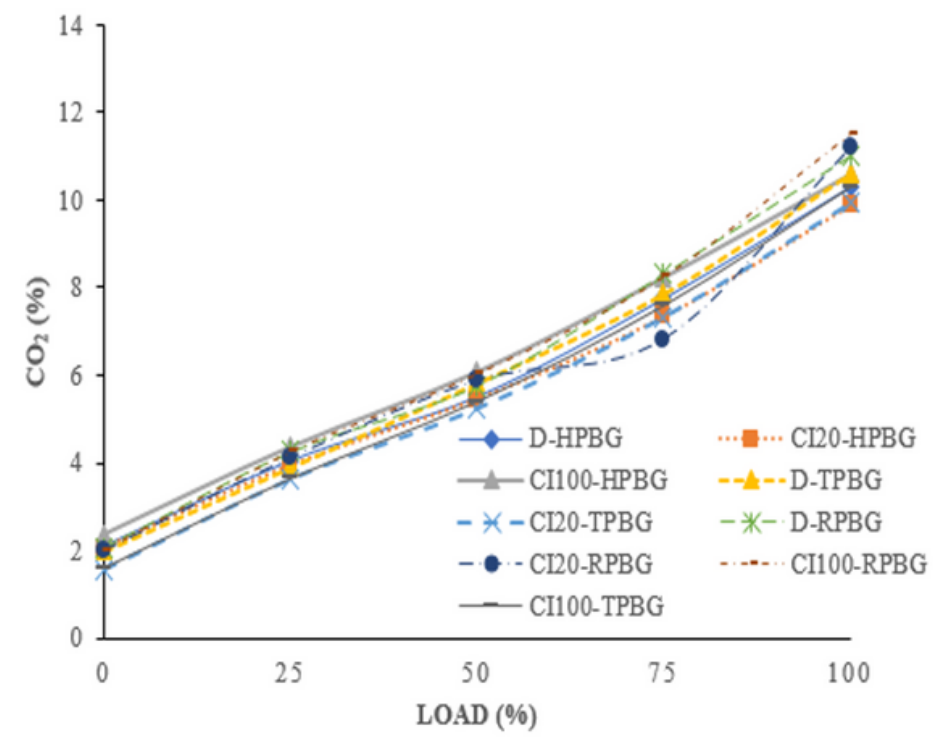

(a)

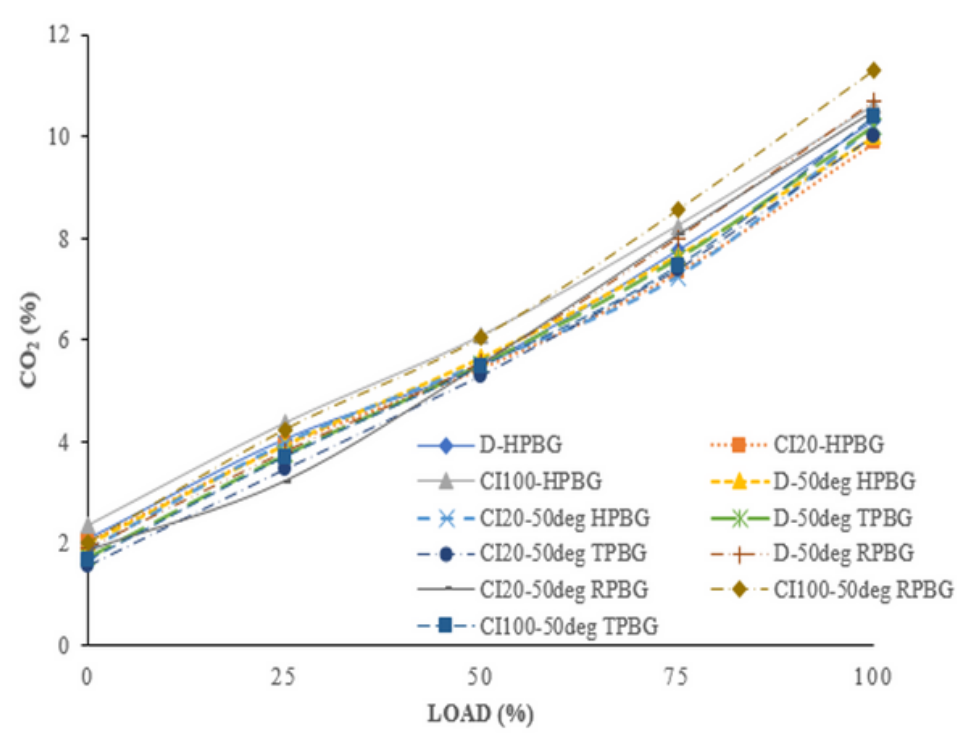

(b)

Figure 16

Impact of different PBG's on $\mathrm{CO} 2$ emission for with and without preheated fuels at varying load conditions

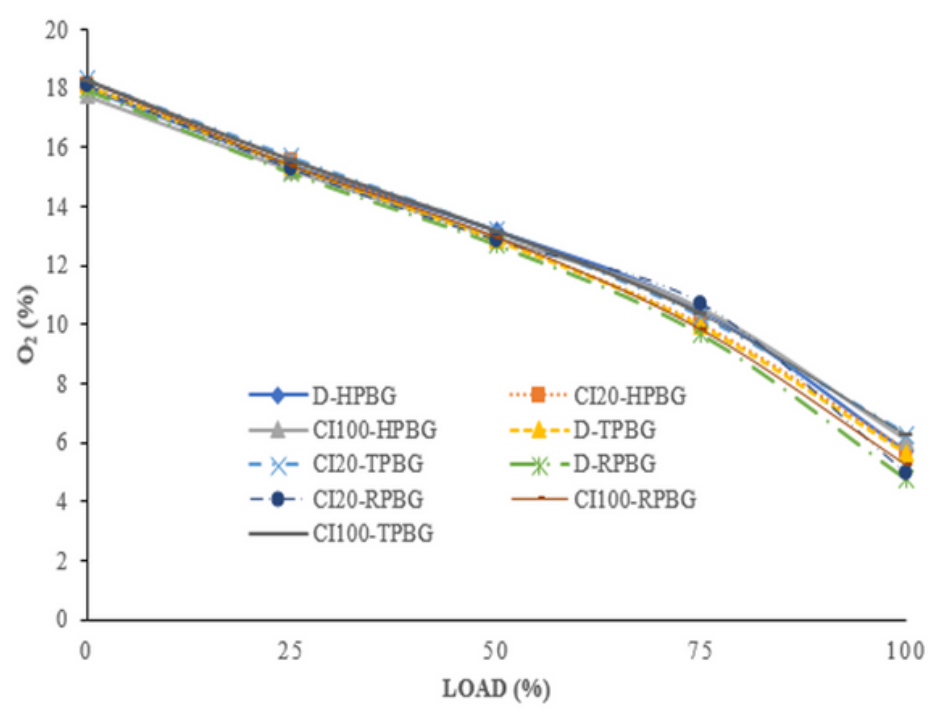

(a)

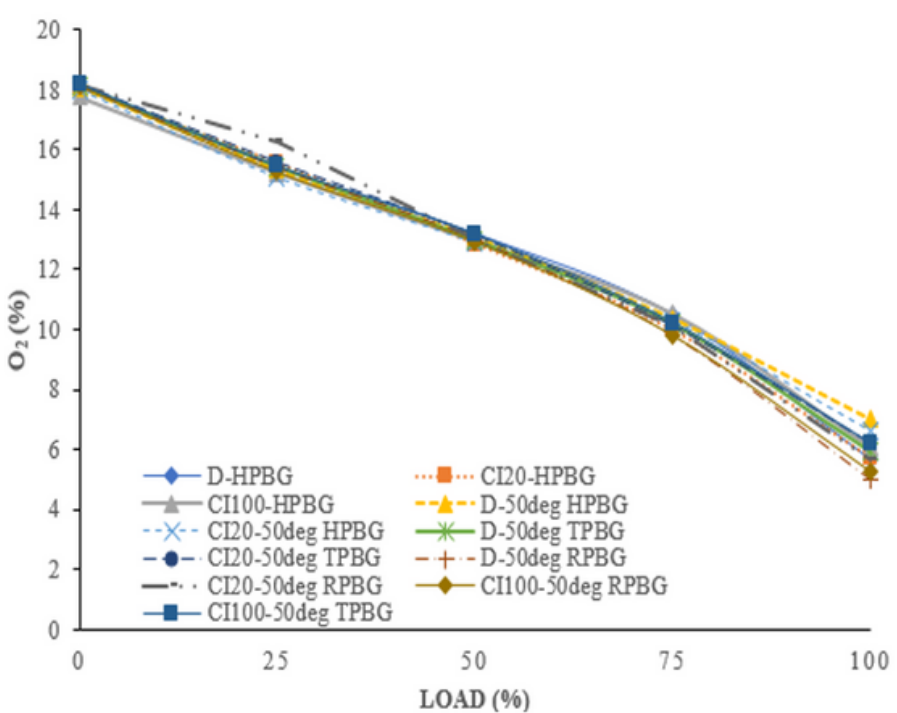

(b)

\section{Figure 17}

Consequences of different PBG's on 02 emission for with and without preheated fuels at varying load conditions 


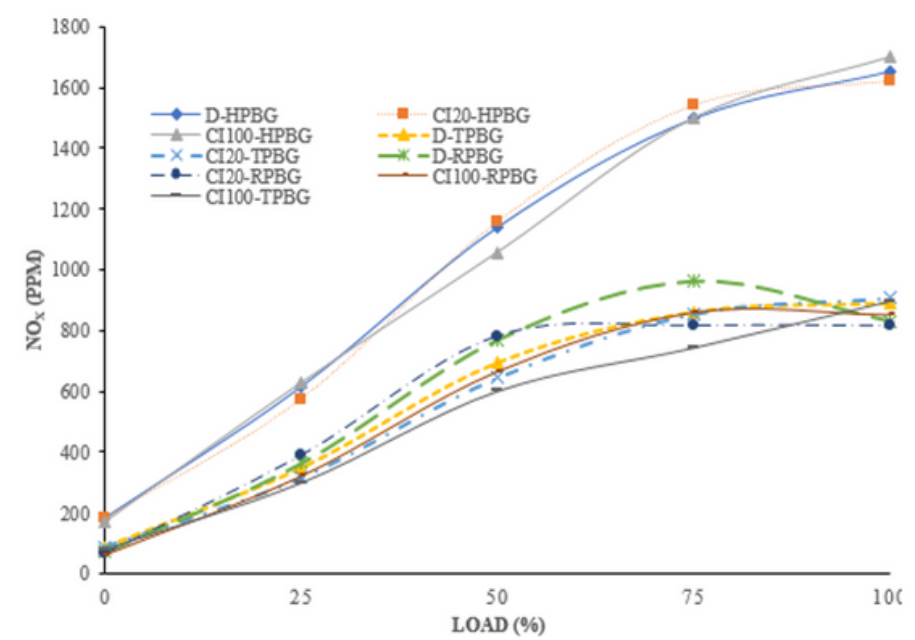

(a)

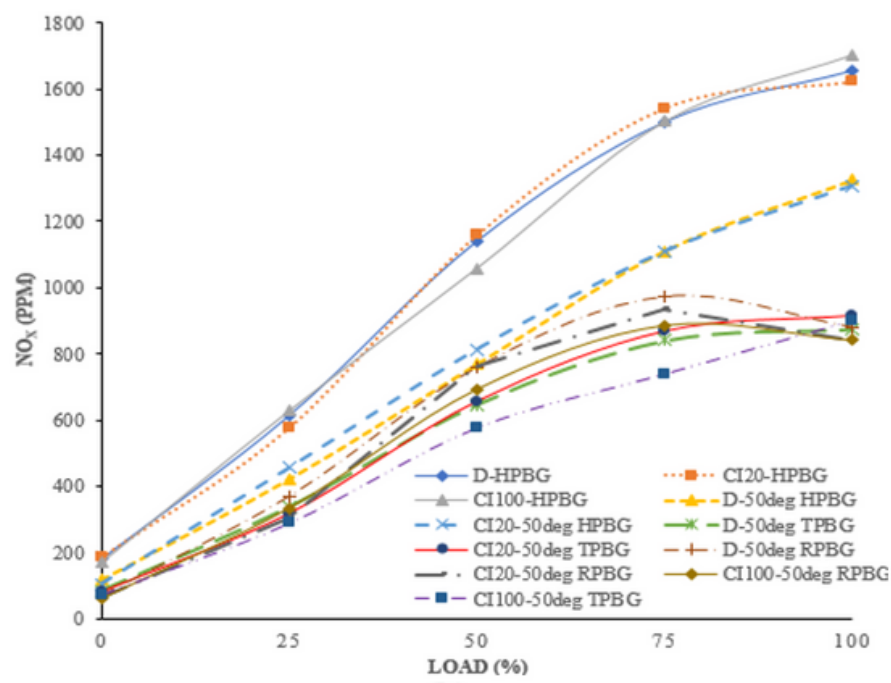

(b)

\section{Figure 18}

Influence of different PBG's on NOx emission for with and without preheated fuels at varying load conditions

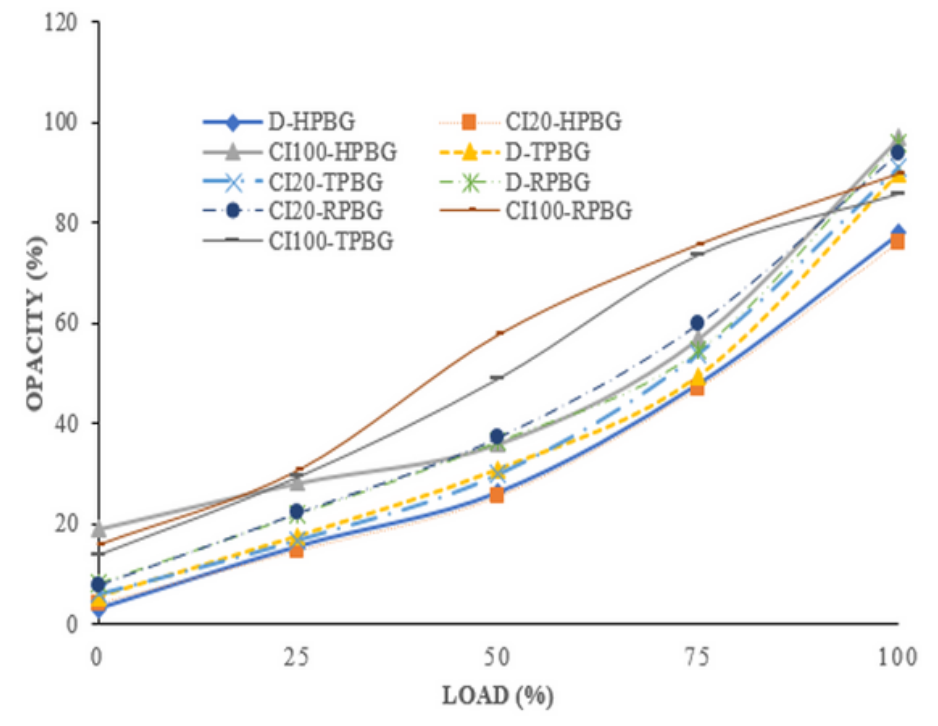

(a)

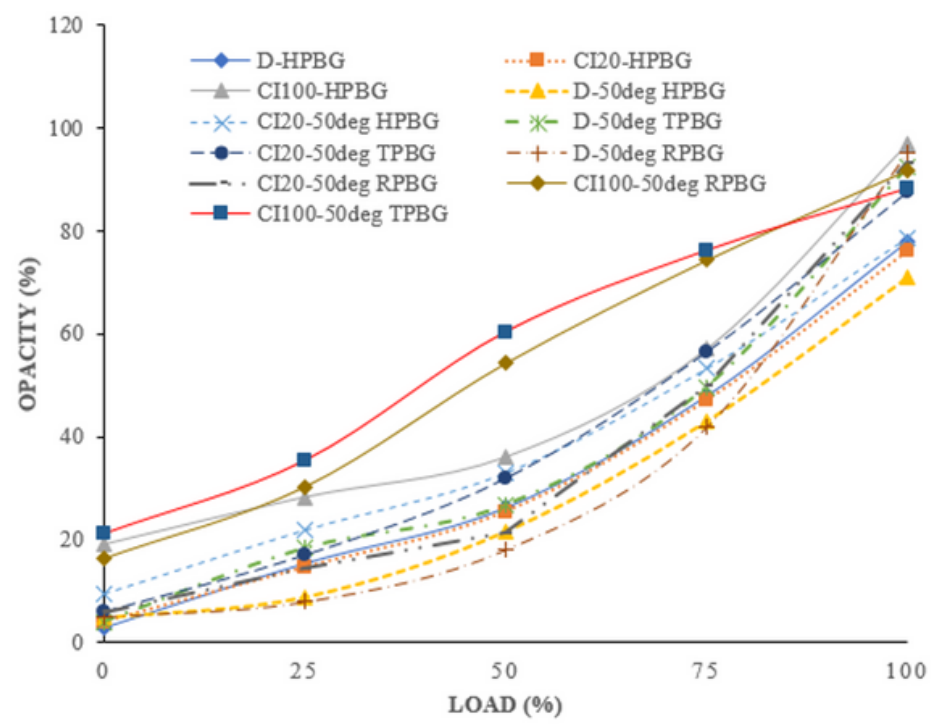

(b)

\section{Figure 19}

Effect of different PBG's on Opacity for with and without preheated fuels at varying load conditions 


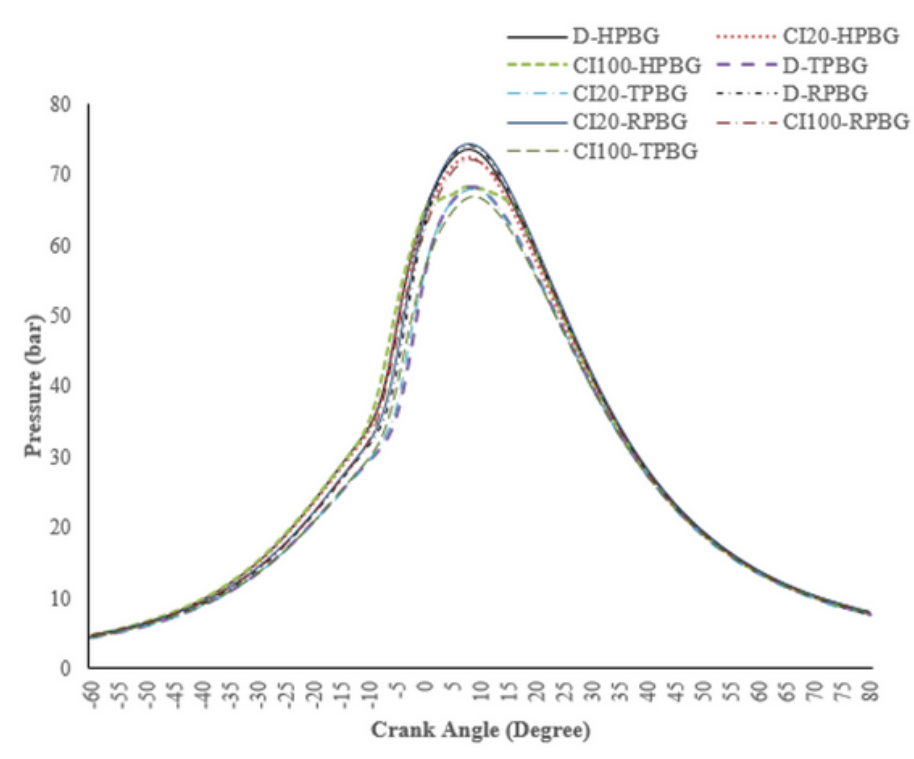

(a)

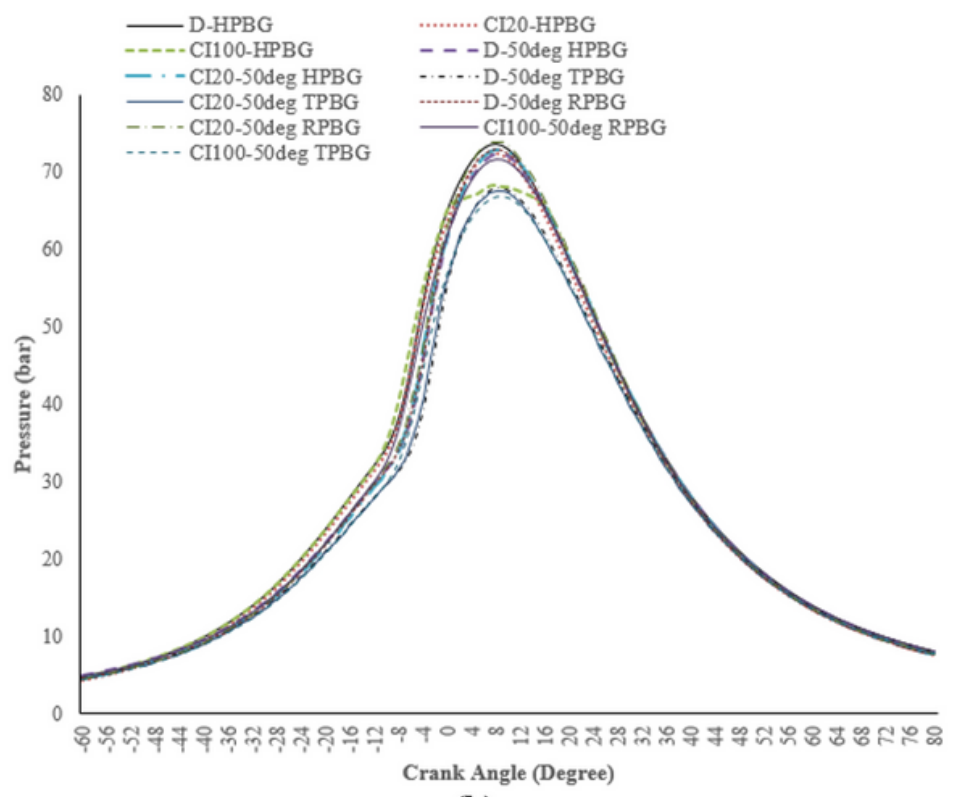

(b)

Figure 20

Ascendancy of different PBG's on Cylinder pressure for with and without preheated fuels at $100 \%$ Engine load conditions

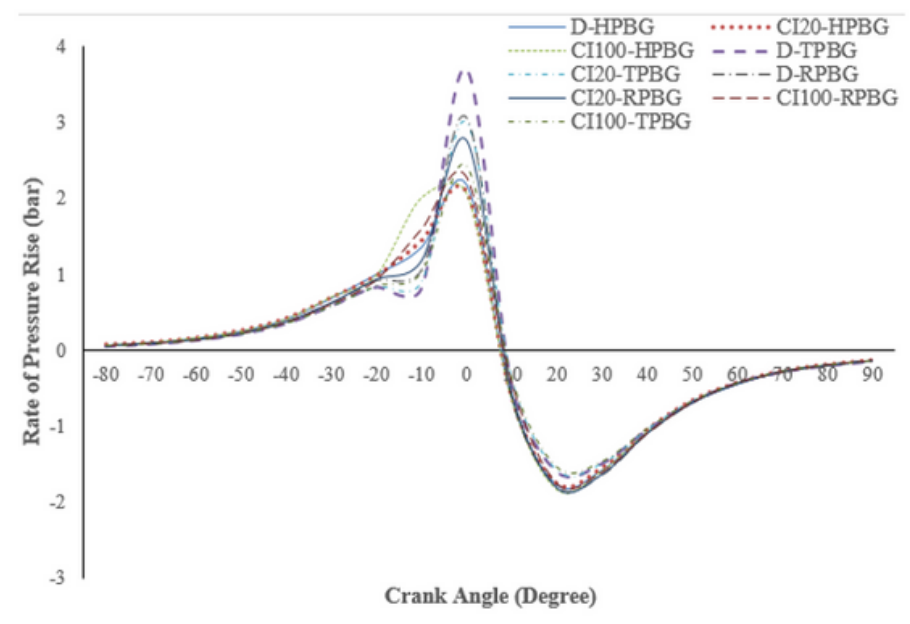

(a)

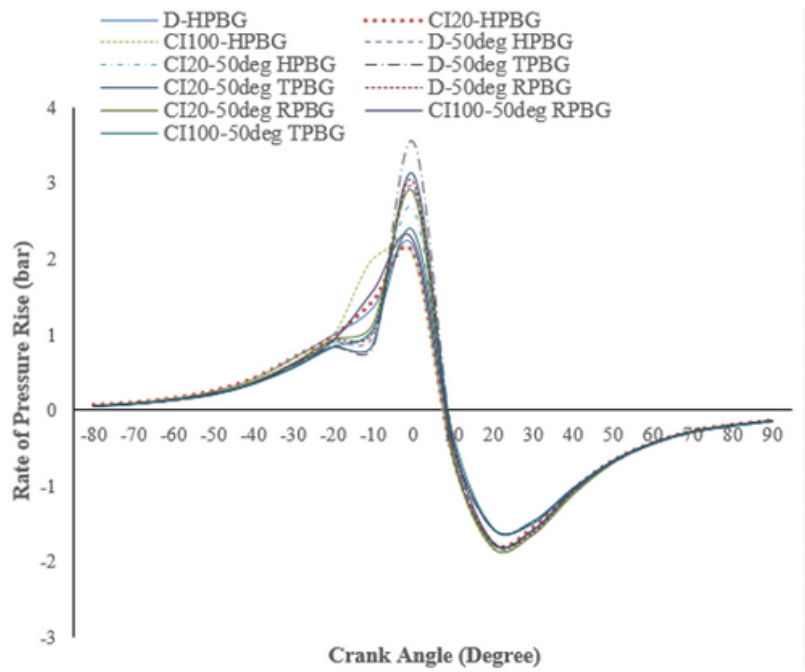

(b)

\section{Figure 21}

Impact of different PBG's on Cylinder pressure for with and without preheated fuels at $100 \%$ Engine load conditions 


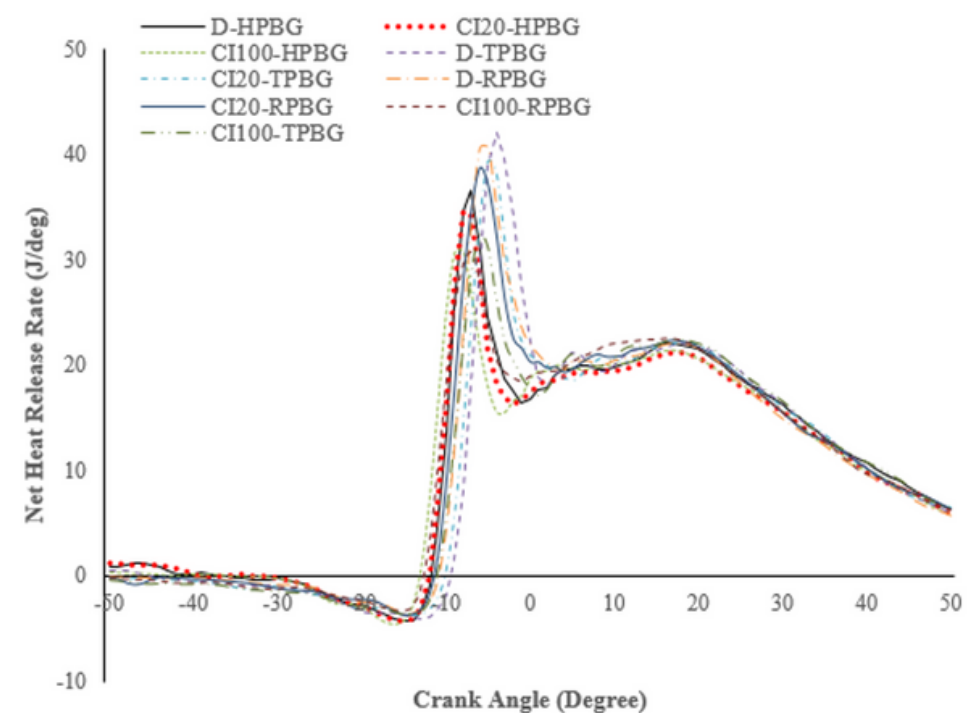

(a)

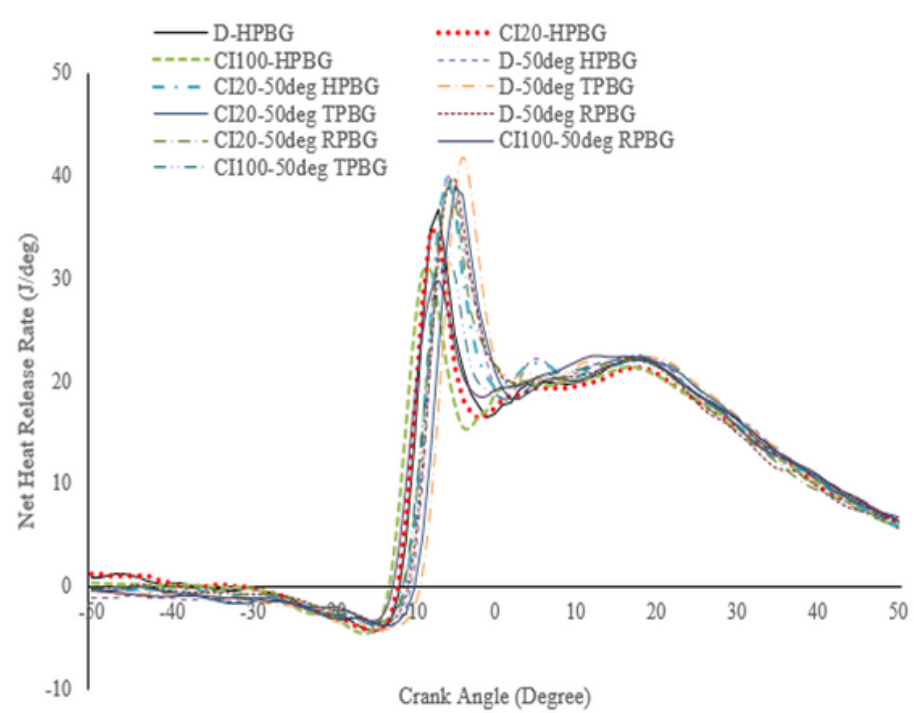

(b)

\section{Figure 22}

Influence of different PBG's on Net Heat Release Rate for with and without preheated fuels at $100 \%$ Engine load conditions

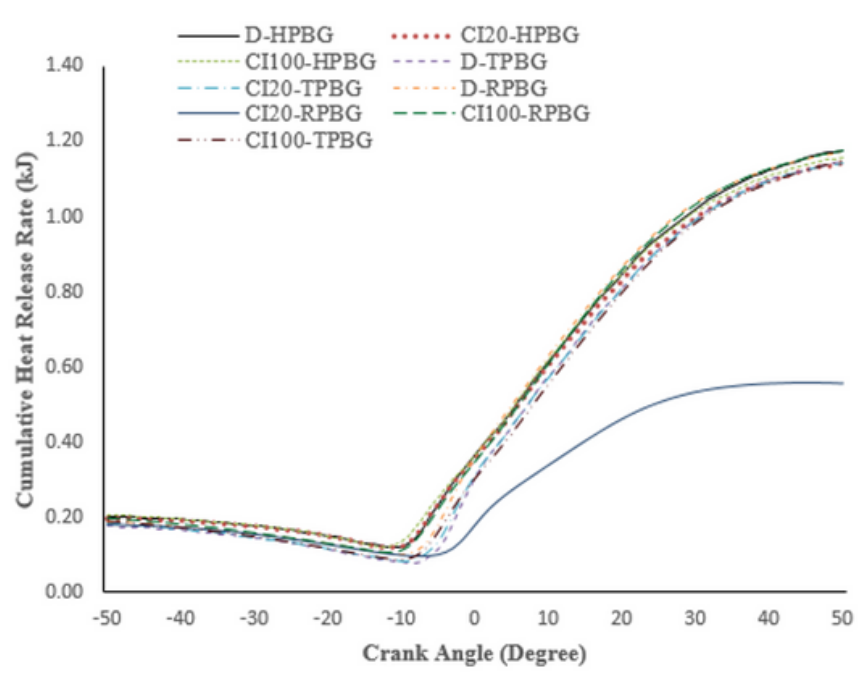

(a)

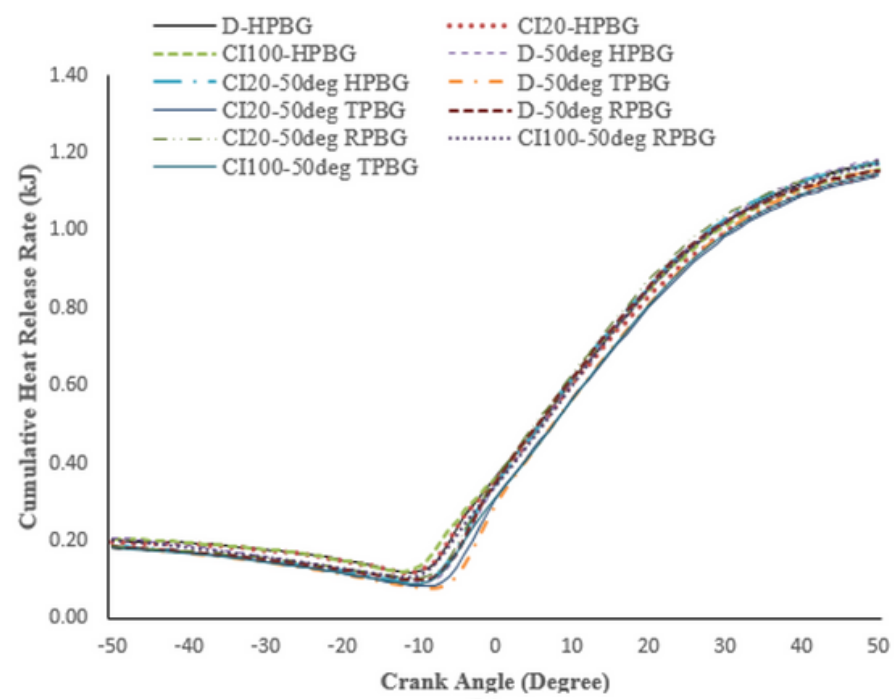

(b)

\section{Figure 23}

Effect of different PBG's on Cumulative Heat Release Rate for with and without preheated fuels at $100 \%$ Engine load conditions 


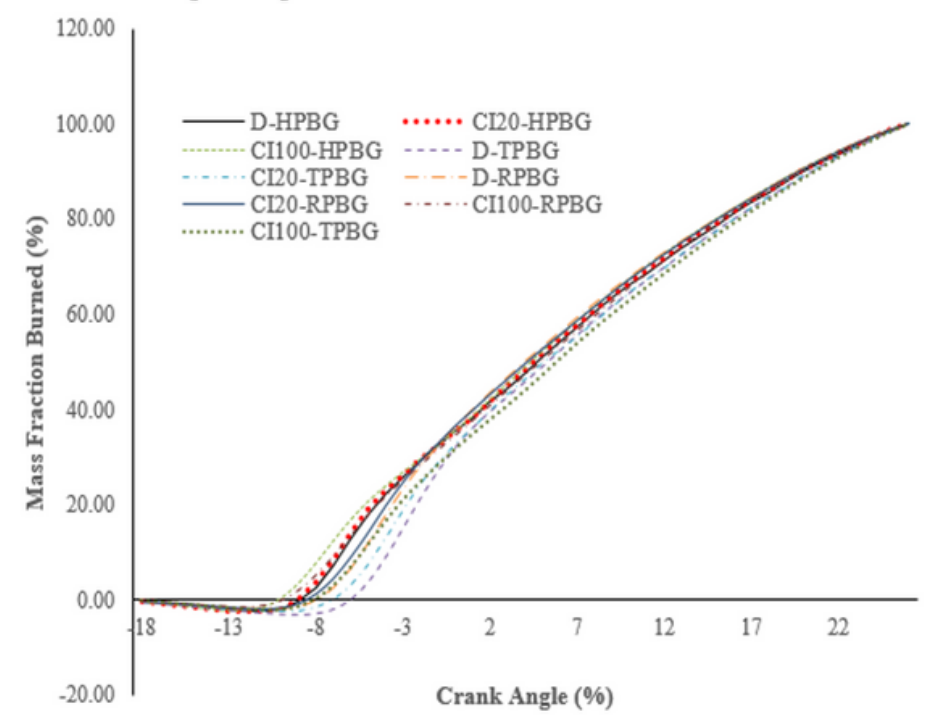

(a)

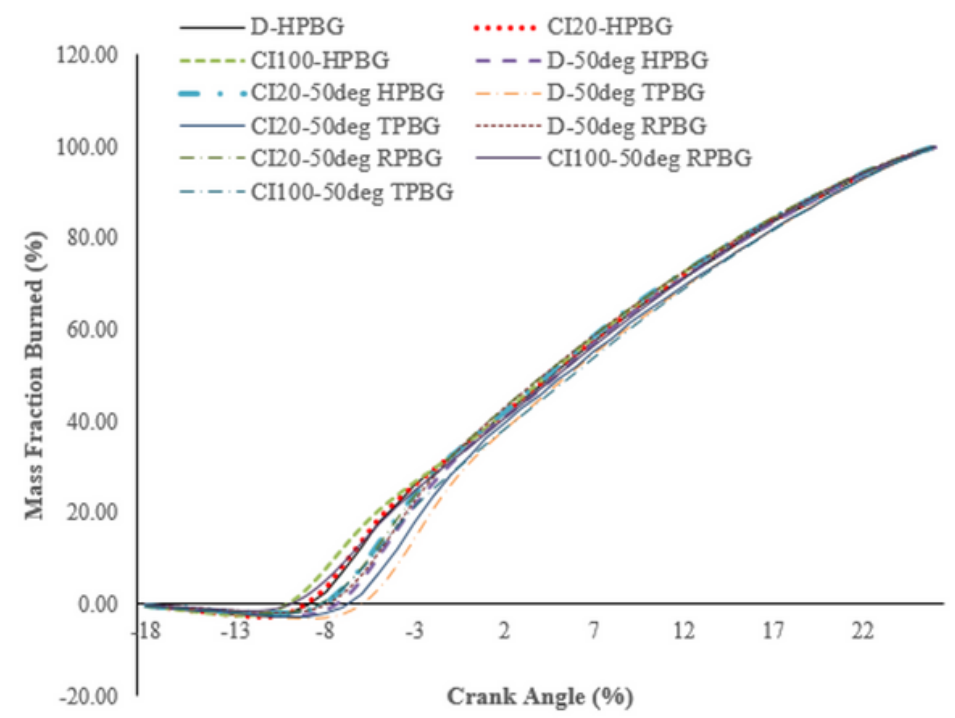

(b)

\section{Figure 24}

Impact of different PBG's on Mass Fraction Burned for with and without preheated fuels at $100 \%$ Engine load conditions

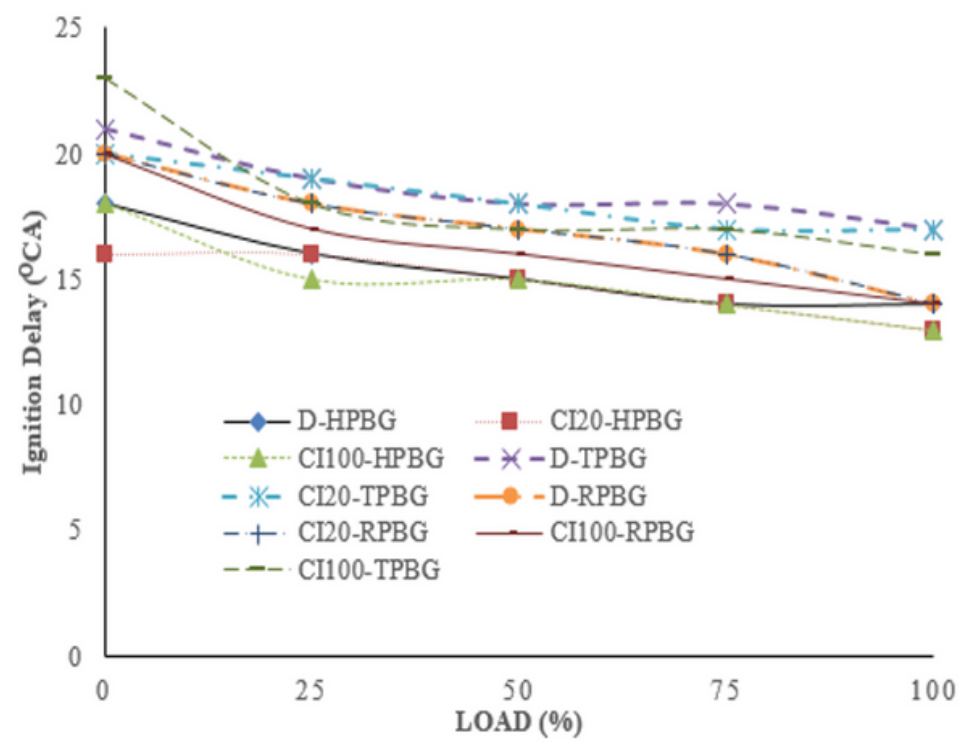

(a)

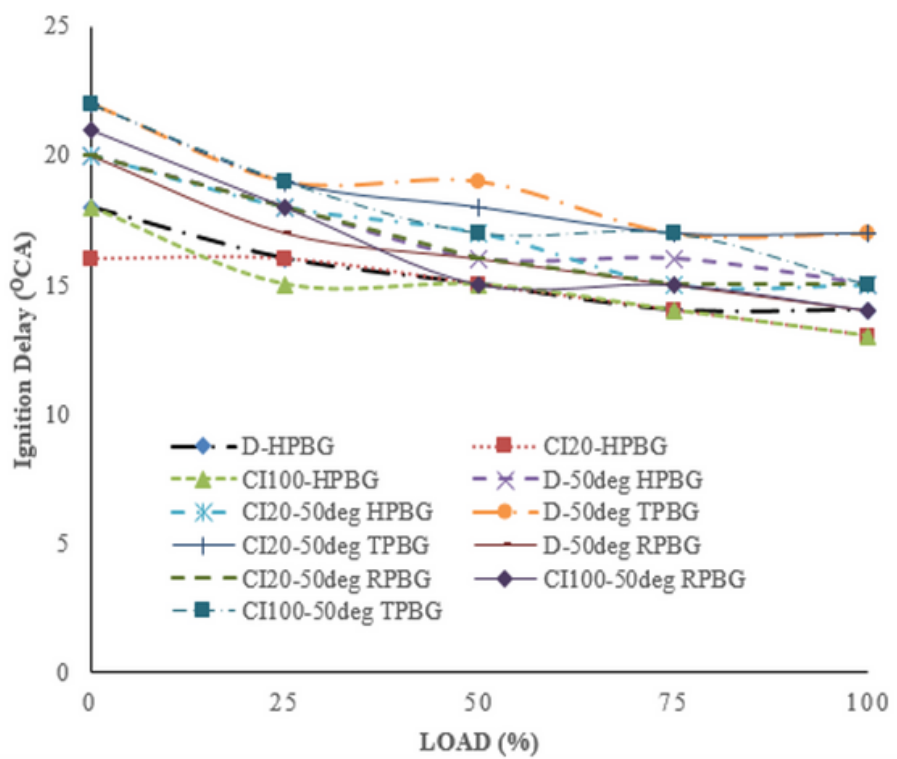

(b)

\section{Figure 25}

Influence of different PBG's on Ignition delay for with and without preheated fuels at $100 \%$ Engine load conditions 


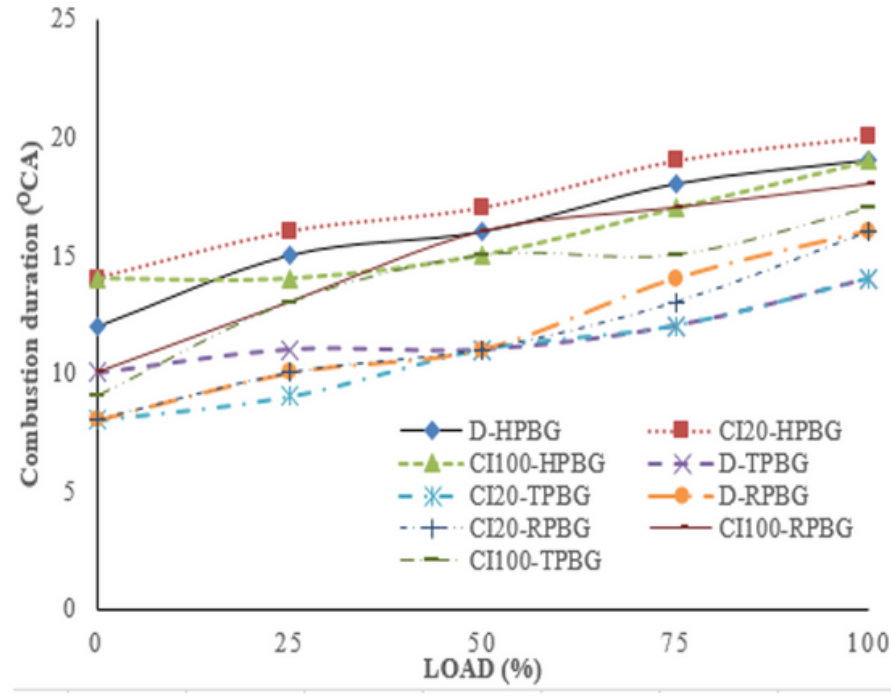

(a)

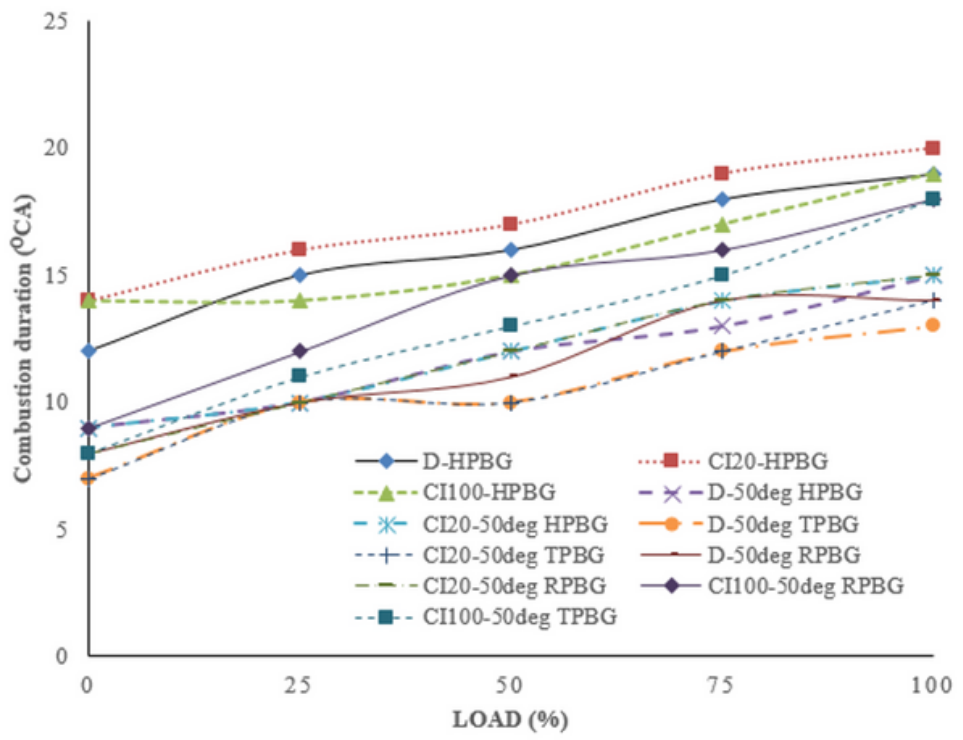

(b)

Figure 26

Effect of different PBG's on Combustion Duration for with and without preheated fuels at $100 \%$ Engine load conditions 